\title{
II.
}

\section{Zur Kenntniss der Bedeutung des Fettes und seiner Componenten für den Stoffwechsel.}

\author{
Von Dr. Immanuel Munk, \\ Assistenten am physiologischen Laboratorium der $¥$. Thierarzneischnle $z u$ Berlin.
}

1. Die Resorption der Fettsäuren und ihre Verwerthung im Organismus.

Die hohe Bedeutung, die für die Vorgänge der Ernährung den Fetten unzweifelhaft zukommt, ermangelt noch des ausreichenden Verständnisses der ursächlichen Verhältnisse. Im Wesentlichen sind es zwei Thatsachen, die in dieser Hinsicht als festgestellt gelten dürfen. Einmal dient das Nahrungsfett, soweit es in die Körpersäfte übertritt, zum directen Ersatz von bei den Stoffwechselprozessen verbrauchtem Fettgewebe, ferner ist das Fett als ein vorzügliches Sparmittel anzuseben, insofern Fettzufuhr den Eiweissverbrauch des Körpers herabsetzt, und zwar, wie dies C. Voit scharf dargethan hat, in weit höherem Grade, als dies bei Zufuhr der gleichen Menge von Kohlehydraten oder Leim der Fall ist. Kann auch kein Zweifel darüber walten, dass es wesentlich zwei Formen sind, in welchen die Resorption des Nahrungsfettes im Darmrohr erfolgen kann, nehmlich als Neutralfett in emulgirter Form oder nach vorgängiger Spaltung in fette Säuren und Glycerin, welch' letzterer Wirkung sowohl der Bauchspeichel wie das Fäulnissferment im Darme fähig ist, so sind wir doch noch im Unklaren darüber, in welchem Umfang die Emulgirung und in welchem die Spaltung der Felte im Darmrohre erfolgt. Bald hat man angenommen, dass der grösste Theil des Fettes der Spaltung anheimfällt und dass die hierbei frei werdenden Fettsäuren, von dem Alkali der Galle und des Bauchspeichels gebunden, als Seifen der Resorption zugänglich werden, bald hat man wiederum diesem Factor nur einen ganz untergeordneten Werth beigemessen. Ziemlich allgemein neigt man neuerdings mehr und mehr der Ansicht zu, dass das Nahrungsfett im 
Darme in überwiegender Menge unangegriffen bleibe und als Fettemulsion in den Chylus übertrete. Der Hauptvertreter der ersteren Anschaunng, Radziejewski ${ }^{1}$ ), versuchte den Beweis dafür in der Weise zu führen, dass er statt des Fettes Seifen an Hunde verfütterte; aus dem danach constatirten Ansatz von Körperfett bei den zuvor mageren Hunden glaubte er den directen Uebergang der verfütterten Seifen in Körperfett erschliessen zu können. Indess ist dieser Schluss nicht einwandfrei; die Seifen könnten nehmlich in der Weise gewirkt haben, dass sie anstatt des, in der Norm aus dem Eiweiss im Körper hervorgehenden und durch die Stoffwechselprozesse sonst wieder verbrauchten Fettes zersetzt worden sind, dass also die Seifen, wie man sich auszudrücken pflegt, den Fettverbrauch im Körper beschränkt haben. Röhrig ${ }^{2}$ ) hinwiederum hat sich bemüht nachzuweisen, dass ein Uebertritt von Seifen aus dem Darm - sei es direct durch die Pfortaderwurzeln oder auf dem Umwege durch den Chylus - in's Blut in irgend beträchtlichen Mengen nicht füglich angenommen werden darf, weil bei dem Gehalt des Blutserum an Kalksalzen aus den löslichen Alkaliseifen unlösliche Kalkseifen entstehen müssten. Alle diese Versuche sowie die sich daran knüpfenden Betrachtungen und Folgerungen fussen auf der Anschauung, dass die im Darmrobr abgespaltenen Fettsäuren, um in die Säfte übertreten zu können, vollständig in die löslichen und diffusiblen Alkaliverbindungen, Seifen verwandelt werden müssten. Eine reichliche Fettfütterung und eine umfangreiche Spaltung der Fette im Darme vorausgesetzt, würde es zur Bildung von Seifen sehr erheblicher Mengen von Alkalien bedürfen, unter Umständen mehr, als dem Darm und vielleicht dem Organismus äberhaupt davon zur Verfügung steht. Ueber diese und ähnliche Bedenken schienen Fütterungsversuche mit reinen Fettsäuren entscheiden zu können; auch durfte man von ihnen einen Beitrag zur Lösung der Frage erwarten, in welcher Form thatsächlich der Uebertritt der Fette aus dem Darm in die Säfte erfolgt.

Alle thierischen Fette sind bekanntlich ein Gemenge von Oleïn, Palmitin und Stearin ${ }^{3}$ ), von denen nur ersteres bei gewöhnlicher

1) Dieses Archiv 1868. Bd. 43 S. 268-286.

2) Arbeiten aus der physiol. Anstalt zu Lejpzig. IX. 1874. S. 1-23.

3) Daneben finden sich in der Butter Butyrin, Capronin u. a., nacb We in auch Myristin und Arachin. Myristin ist vorwiegend im Bienenwachs enthalten. 
Temperatur flüssig ist. Das Palmitin schmilzt erst bei $46^{\circ} \mathrm{C}$., das Stearin bei $53^{\circ}$. Das Oleïn löst Palmitin und Stearin reichlich auf and diese Mischung hat je nach ihrem Gehalt an olein einen entsprechend niedrigeren Schmelzpunkt, so liegt der des Schweinefettes, das übrigens überwiegend aus Palmitin und Oleîn besteht und nur wenig Stearin enthält, etwa bei $34^{01}$ ). Ihrer chemischen Constitution nach sind die Fette als zusammengesetzte Aether anzusehen und zwar als die Fettsäureäther des Glycerin, sie heissen deshalb auch Triglyceride. Aus dem Glycerin $\mathrm{C}_{3} \mathrm{H}_{5}(\mathrm{HO})_{3}$ lassen sie sich durch Substitution des $\mathbf{H}$ vom Hydroxyl durch das Fettsäureradical ableiten, z. B. Palmitin $\mathrm{C}_{3} \mathrm{H}_{5}\left(\mathrm{C}_{16} \mathrm{H}_{31} 0.0\right)_{3}$. Die Palnnitinsäure $\mathrm{C}_{16} \mathrm{H}_{32} \mathrm{O}_{2}$, die Stearinsäure $\mathrm{C}_{18} \mathrm{H}_{36} \mathrm{O}_{2}$ und die Oelsäure $\mathrm{C}_{18} \mathrm{H}_{34} \mathrm{O}_{2}$ theilen mit ihren Glyceriden, dem Palmitin, Stearin und Olein eine Reihe von physikalischen Eigenschaften. Nur die Oelsäure ist, wie das 0leün, bei gewöhnlicher Temperatur flüssig, der Schmelzpunkt der festen fetten Säuren ist höher als der ihrer Glyceride, so liegt der der Palmitinsäure bei $62^{\circ}$, der Stearinsäure bei $69^{\circ}$; die beiden letzteren sind krystallinisch und werden ebenso wie das bei den Glyceriden der Fall ist, von der Oelsäure reichlich aufgelöst. Der Schmelzpunkt eines solchen Gemisches retter Säuren liegt um so niedriger, je mehr Oelsäure, und um so höher, je mehr Stearinsäure darin enthalten ist. Das Gemisch der Fettsäuren, das aus Schweinefett darstellbar ist, fängt, wie ich mich uberzeugt habe, zwischen $35^{\circ}$ und $37^{\circ}$ zu schmelzen an, ist also bei der Temperatur des Thierkörpers noch flüssig. Die Fettsäuren sind, ebenso wie ihre Glyceride unlöslich in Wasser, dagegen sämmtlich löslich in Aether. Was die Mengen anlangt, in welchen sich die in Wasser unlöslichen fetten Säuren in den thierischen

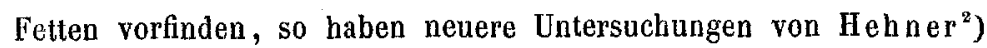
und Kretzschmar ${ }^{3}$ ) die bemerkenswerthe Thatsache ergeben, dass der Gehalt an unlöslichen Fettsäuren bei den verschiedensten Fetten - die Butter ausgenommen - nur zwischen 95,2 und 95,9 pGit.

1) Das Schweinefett hat, je nach selnem Standorte: Unterhautgewebe, Bauchböhle etc. einen wechselnden Gehalt an Oleïn und Palmitin und einem dementsprechend zwischen $30^{\circ}$ und $41^{\circ}$ schwankenden Schmelzpunkt; das sog. Nierenfett ist noch bei $30^{\circ}$ flüssig.

2) Zeitschr. f. analyt. Chem. XVI. S. 145.

3) Berichte d. deutsch. chem. Gesellsch. X. S. 2091. 
schwankt ${ }^{1}$ ). Der Rest von $4,1-4,8$ pCt. besteht fast nur aus Glycerin und Spuren flüchtiger Fettsäuren ${ }^{2}$ ).

Wässrige Lösungen von Pflanzenschleim oder Eiweiss halten bekanntlich flüssige Fette fein vertheilt suspendirt, bilden mit ihnen sog. Emulsionen, die in der Regel ein milchiges Ausseben darbieten, ebenso geben verdünnte Lösungen von Aetz- oder kohlensauren Alkalien mit Fetten geschüttelt, Emulsionen. Die physikalischen Bedingungen für die Emulgirung von Fett bei blosser Berührung mit sehr verdünnten Lösungen kohlensaurer Alkalien, sowie den Einfluss des Pancreassaftes resp. der Galle auf die Emulsionsbildung haben neuerdings J. $\mathrm{Gad}^{3}$ ) und G. Qu in $\mathrm{cke}^{4}$ ) eingehend ermitteit; es sei dieserhalb auf ihre Originalarbeiten verwiesen. Von Herrn Prof. E. Salkowski auf die Emulgirbarkeit der Oelsäure durch verdünnte Sodalösung aufmerksam gemacht, habe ich durch eine Reihe von Versuchen festgestellt, dass wie die in Wasser unlöslichen Fettsäuren mit den resp. Fetten in einer Reihe physikalischer Eigenschaften übereinstimmen, so auch die Bedingungen für die Emulgirung derselben durch Eiweiss- und Alkalilösungen sehr ähnliche sind. Bringt man $\frac{1}{2} \mathrm{Grm}$. Fettsäuren ${ }^{5}$ ) mit $20 \mathrm{Gem}$. einer Lösung von Serumalbumin, etwa einer 7 procentigen, bei einer Temperatur zusammen, bei der die Fettsäuren sich vertlüssigen, und schüttelt die Mischung, so erhält man eine gute Emulsion von milchweissem Aussehen. Da nun die Serumalbuminlösung nur wenig freien Alkalis enthält - von der hierzu benutzten Lösung enthielten $20 \mathrm{Ccm}$. eine, $0,45 \mathrm{Ccm}$. einer Zehntelnormalsäure entsprechende Menge freien Alkalis d. j, etwa $2 \mathrm{Mgrm}$. NaHO -, so kann selbstverständlich nicht davon die Rede sein, dass die freien

1) Die Butter enthält erheblich weniger unlösliche fette Säuren, nach Hehner nur etwa 86 pCt., nach Kretzschmar bis zu 89,5 pCt.

2) Flüchtige fette Säuren (Butter-, Capron-, Caprylsäure u. a.) finden sich reichlich nur in der Butter, nach Hehner, auf Buttersäure berechnet; zu 4,8-7,4 pCt.

3) du Bois-Reymond's Arch. f. Physiol. 1878. S. 181.

4) Arch. f. d. ges. Physiol. XIX. S. 129-44.

5) Zu allen nachfolgend beschriebenen Versuchen diente das Gemisch von Fettsäuren, das aus dem Schwetnefett gewonnen wird. Selbstverständlich wird das Nehmliche anch für die Fettsäuren der übrigen thierischen Fette getten, nur dass je nach dem Schmelzpunkt des resp. Fettsäuregemischs die Temperatur, bei der die Versuche anzustellen sind, zu variiren sein wird. 
Fettsäuren verseift sind. Ein kleiner Theil von ihnen, auf Palrnitinsäure berechnet etwa $0,015 \mathrm{Grm}$. entsprechend $2 \mathrm{Mgrm}$. NaHO, kann höchstens in die Alkaliverbindung übergegangen sein, die bei weitem grössere Menge ca. $0,48 \mathrm{Grm}$. ist in Form freier Fettsăure von der Eiweiss- und Seifenlösung emulgirt. Dass eine solche Emulgirung freier Fettsäuren stattfindet, davon kann man sicb noch auf einem anderen Wege überzeugen. Setzt man zu $20 \mathrm{Ccm}$. einer $\frac{1}{4}$ procentigen Sodalösung etwa $1 \mathrm{Grm}$. Fettsäuren, so erhält man bei Temperaturen über $35^{\circ}$, die zur Verflüssigung der Fettsäuren erforderlich sind, eine schöne milchweisse Emulsion. Nehmen wir zum Zweck der Berechnung die Fettsäuren als Palmitinsäure an, so würde $1 \mathrm{Grm}$. Palmitinsäure zur Bildung von pałmitinsaurem Natron nach stöchiometrischen Verbältnissen $0,187 \mathrm{Grm} . \mathrm{Na}_{2} \mathrm{CO}_{3}$ erfordern. Unsere Sodalösung enthält aber in $20 \mathrm{Gcm}$. nur $0,05 \mathrm{Grm} . \mathrm{Na}_{2} \mathrm{CO}_{3}$; es ist also klar, dass in der unter diesen Umständen gebildeten Emulsion höchstens $27 \mathrm{pCt}$. von den Fettsäuren verseift sein können, 73 pCt. von ihnen sind als freie Fettsäuren von der Seifenlösung emulgirt. Diese Werthe bezeichnen noch lange nicht die Grenze des in der Emulgirung Erreichbaren; es lassen sich unter den angegebenen Verhältnissen noch grössere Mengen, fast 2 Grm. Fettsäuren emulgiren, sodass wohl die Quantităt der verseiften Säuren bis auf etwa 15 pCt. sich herabdrücken lässt. Da nun abgesehen vom Duodenum, in dem der aus dem Magen übergetretene Chymus mehr oder weniger noch sauer reagirt, bis weiterhin die Säure durch das Alkali der Galle und des Bauchspeichels neutralisirt und überboten wird, im übrigen Dünndarm sich ein alkalischer, eiweisshaltiger Inhalt findet, so können hier die sei es präformirt eingeführten oder aus dem Nahrungsfett durch den Bauchspeichel abgespaltenen Fettsäuren in bei weitem überwiegender Menge emulgirt und so der Resorption durch die Darmzotten zugänglich gemacht werden, ohne dass, wie man sich bisher vorgestellt hat, die gesammten Fettsäuren vom Alkali zu Seifen gebunden werden müssten, vielmehr trifft die Verseifung thatsächlich nur für einen geringen Antheil der Fettsäuren zu.

Die vorstehenden Erfahrungen haben auch noch nach anderer Richtung hin Interesse. Da die in Wasser unlöslichen Fettsäuren sich physikalisch vollständig den Fetten gleich verhalten, da sie ebenso wie diese von alkalischen, von Eiweiss-, Schleim- und Seifen- 
lösungen emulgirt werden, da ferner die Emulsionen des Fettes sich von denen fetter Säuren weder durch das Aussehen, noch mikroskopisch unterscheiden - in beiden siebt man kleine und kleinste Fett- resp. Oeltröpfchen - , so wird man aus dem milchweissen Aussehen einer Flüssigkeit nicht unbedingt auf einen Gehalt an emulgirtem Fett zu schliessen berechtigt sein, vielmehr wird man unter Umständen auch daran denken müssen, dass Fettsäuren darin emulgirt sein möchten. Im Einklang hiermit zeigt der Versuch, dass der nach ausschliesslicher Fütterung mit Albuminaten gewonnene, gelblichweisse, opalescirende Chylus eines Hundes, mit Fettsäuren bei Körpertemperatur versetzt und geschüttelt, milchweiss wird. Ja beides, Emulgirung von Fett und von Fettsäuren wird in einer Flüssigkeit vorkommen können, ohne dass sich dieser Umstand anders als durch die chemische Analyse, die Neutralfett und Fettsäuren von einander zu trennen gestattet, wird erkennen lassen. In der That kommen im Thierkörper unter Bedingungen, von denen später die Rede sein wird, freie Fettsäuren und Neutralfett neben einander in alkalischer Flüssigkeit emulgirt vor.

Nachdem wir nun gesehen, dass die Fettsäuren auf demselben Wege der Aufnahme in die Säfte zugänglich werden können, wie die Fette, fragt es sich, wie gross ist die Resorbirbarkeit der fetten Säuren, wie ihre Ausnutzung im Darme und ihre Verwerthung im Thierkörper. Die Wege, die sich zur Beantwortung dieser Fragen darbieten, sind im Wesentlichen drei: 1) die vergleichende Bestimmung des Gehalts der Fäces an Fettsäuren und Seifen; 2) die Bestimmung der bei Verdauung von Fettsäuren in den Chylus übertretenden Fettkörper (Fette, Fettsäuren, Seifen); 3) die Feststellung der Eiweisszersetzung im Thierkörper einmal nach Fütterung mit Fett und dann nach Fütterung mit den aus der gleichen Fettmenge erhältlichen Fettsäuren.

Es empfiehlt sich für die Darstellung, die Stoffwechselversuche zuerst zu besprechen: Die physiologische Bedeutung des Fettes berubt, wie dies $V_{0}$ it zuerst auf exactem Wege dargethan hat, zum Theil darauf, dass es leichter unter die Bedingungen des Zerfalls geräth und durch seine Zersetzung einen gewissen Antheil vom Eiweiss vor dem Verbrauch schützt ${ }^{1}$ ). Ein grosser Hund von 25 bis

1) Vergl. hierüber die Ausführungen in meiner Arbeit dieses Archiv Bd. 76 S. 122. 
30 Kilo Körpergewicht, der etwa 1200 Grm. Fleisch täglich bedarf, um von dem Eiweissbestande seines Körpers nichts zuzusetzen, kommt ebenfalls in N-Gleichgewicht, wenn er $100 \mathrm{Grm}$. Fett neben nur $800 \mathrm{Grm}$. Fleisch erhält. Es bewirkt also die Beigabe von Fett eine Ersparniss im Eiweissverbrauch von einer gewissen Grösse. Befindet sich nun ein Hund bei einem aus bestimmten Mengen von Fleisch und Fett bestehenden Futter im $\mathrm{N}$-Gleichgewicht und reicht man inm dann statt des Fettes die in der gleichen Fettmenge enthaltenen fetten Säuren, so wird die Grösse der Eiweisszersetzung, die jetzt statthat, im Vergleich mit der bei Fettfütterung gefundenen den Maassstab für die physiologische Bedeutung der Fettsäuren im Verhältniss zu der des Fettes abgeben können. Hieraus lässt sich einfach folgende Versuchsanordnung ableiten: Eine für derartige Versuche eingeübte Hündin von etwa 25 Kilo wurde mit einem aus $800 \mathrm{Grm}$. Fleisch und $70 \mathrm{Grm}$. Fett bestehenden Futter in N-Gleichgewicht gebracht, dann erhielt sie durch einige Tage hindurch statt des Fettes die darin enthaltenen Fettsäuren, hierauf folgte eine Periode der Fettfütterung, dann wieder eine Periode, wo Fettsäuren gereicht wurden; die Versuchsreihe wurde mit Verfütterung von Fett geschlossen. Der Harn wurde, wie in den früheren, von mir angestellten Stoffwechselversuchen, durch den Katheter gewonnen, die Abgrenzung der auf die einzelnen Perioden entfallenden Kothmengen durch eingeführte Korkstücke bewirkt ${ }^{1}$ ). Sowohl im Harn als im Koth wurde der $\mathrm{N}$-Gehalt bestimmt, in beiden durch Glüben mit Natronkalk und zwar im Harn direct nach Seegen, im Koth nach vorgängigem Trockneo und Pulverisiren desselben. Ausserdem wurde täglich das Körpergewicht des Thieres festgestellt. Die Fettsäuren wurden so gewonnen: Diejenige Fettmenge - es wurde durchgehends Schweinefett angewendet -, welche sich neben dem Fleisch zur Erhaltung von $\mathrm{N}$-Gleichgewicht als ausreichend erwiesen hatte $(70 \mathrm{Grm}$., in einem später anzüührenden Versuche $100 \mathrm{Grm}$.), wurde mit starker Natronlauge 3 bis 4 Stunden lang gekocht, alsdann die Seifenlösung mit verdünnter Schwefelsäare bis zur sauren Reaction versetzt; in der Kälte erstarrten die sich ausscheidenden Fettsäuren. In der Regel erst am darauf folgenden

1) Vergl. hierüber dieses Archiv Bd. 76 S. 125 und Zeitschr. f. physiol. Chem. II. S. 31. Ich komme übrigens am Schluss der Mittheilung noch auf diesen Punkt zurück. 
Tage wurden die festen Fettsäuren auf ein Faltenfilter gebracht und mit kaltem Wasser so lange ausgewaschen, bis das Waschwasser keine Reaction auf Schwefelsäure gab. Von dem dann an der Luft getrockneten Filter lassen sich die Fettsäuren obne Verlust entfernen. Wie in der Vorperiode, wurde auch hier das Fleisch mit 300-400 Ccm. Wasser kurze Zeit aufgekocht, die festen Fettsäuren darin geschmolzen und das Futtergemisch lauwarm dem Hunde gereicht. Auch bier hat sich die bereits früher von mir empfohlene Methode, schlecht schmeckende oder riechende Stoffe Hunden in der von ihnen sehr gern genommenen Fleischbrühe zu verabreichen, durchaus bewährt. In dieser Form gereicht haben von 9 Hunden 8 die Fettsäuren obne Widerwillen genommen und nur ein Thier, das übrigens schon 2 Tage vorher zu einem anderen Versuche gedient hatte und vielleicht noch nicht ganz bei gutem Befinden und Appetit war, verschmähte das Futter.

I. Versuchsreihe. Dänische Dogge.

$800 \mathrm{Grm}$. Fleisch, $400 \mathrm{Ccm}$. Wasser.

\begin{tabular}{|c|c|c|c|c|c|c|}
\hline Datum. & Periode. & Verfüttert. & $\begin{array}{l}\text { Harnmenge } \\
\text { in } \mathrm{Ccm} \text {. }\end{array}$ & N im Harn. & N im Koth. & $\begin{array}{l}\text { Körpergew. } \\
\text { in Kilo. }\end{array}$ \\
\hline $\begin{array}{l}1878 . \\
6 . \text { Decbr. } \\
7 . \quad- \\
8 . \quad- \\
9 . \quad-\end{array}$ & I. & je $70 \mathrm{Grm}$. Fett & $\begin{array}{l}589 \\
552 \\
628 \\
598\end{array}$ & $\begin{array}{l}26,208 \\
28,448 \\
28,7 \\
27,58\end{array}$ & $\left.1,424^{1}\right)$ & $\begin{array}{l}25,23 \\
25,16 \\
25,09 \\
24,94\end{array}$ \\
\hline $\begin{array}{l}10 . \\
11 . \quad- \\
12 . \quad-\end{array}$ & II. & $\begin{array}{l}\text { Fettsäuren von } \\
\text { je } 70 \mathrm{Grm} \text {. Fett }\end{array}$ & $\begin{array}{l}586 \\
431 \\
452\end{array}$ & $\begin{array}{l}28,672 \\
27,104 \\
27,084\end{array}$ & $\left.1,454^{2}\right)$ & $\begin{array}{l}24,84 \\
24,75 \\
24,69\end{array}$ \\
\hline $\begin{array}{ll}13 . & - \\
14 . & -\end{array}$ & III. & je 70 Grm. Fett & $\begin{array}{l}483(?) \\
506 \\
571\end{array}$ & $\begin{array}{l}26,488 \\
26,9 \\
28,128\end{array}$ & $1,32^{3}$ ) & $\begin{array}{l}24,59 \\
24,48 \\
24,53\end{array}$ \\
\hline $\begin{array}{l}16 . \quad- \\
17 . \quad- \\
18 . \quad-\end{array}$ & IV. & $\begin{array}{l}\text { Fettsäuren aus } \\
\text { je } 70 \mathrm{Grm} \text {. Fett }\end{array}$ & $\begin{array}{l}569 \\
633 \\
628\end{array}$ & $\begin{array}{l}26,992 \\
28,616 \\
28,367\end{array}$ & $\left.1,29^{4}\right)$ & $\begin{array}{l}24,38 \\
24,36 \\
24,32\end{array}$ \\
\hline $\begin{array}{l}19 . \quad- \\
20 . \quad-\end{array}$ & V. & je 70 Grm. Fett & $\begin{array}{l}609 \\
576\end{array}$ & $\begin{array}{l}29,288 \\
27,412\end{array}$ & $\left.0,86^{5}\right)$ & $\begin{array}{l}24,32 \\
24,20\end{array}$ \\
\hline
\end{tabular}

1) Trockengewicht des Koths $=32,4$ Grm. mit 4,4 pCt. N.

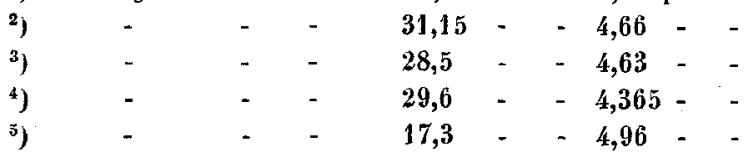

Archiv f. pathol. Anat. Bd. LXXX. Hit. 1 . 
Betrachten wir zunäcbst die N-Ausscheidung in den Perioden der Fettfütterung (Pex. I, III, V). Es wurde entleert

in Per. $I$ in 4 Tagen $110,94 \mathrm{~N}$ durch den Harn, 1,424 $\mathrm{N}$ mit dem Koth

- - III - 3 - 81,516 - - - - 1,32 - - -

- V - $2-56,7-\ldots$ - $-0,86$

also bei Fettfütterung in 9 Tagen $249,156 \mathrm{~N}$ mit dem Harn, 3,604 N mit dem Koth oder im Mittel täglich 27,684 - - - - 0,4 - - - -

zusammen also 28,084 N. 800 Grm. Pferdefleisch enthalten (den $\mathrm{N}$-Gehalt des Fleisches nach $\mathrm{V}_{0}$ it zu 3,4 pGt. angesetzt) $27,2 \mathrm{~N}$, somit bestand annähernd N-Gleichgewicht.

Bei Fütterung mit Fettsäuren wurden ausgeschieden

in Per. II in 3 Tagen $82,86 \mathrm{~N}$ mit dem Harn, $1,454 \mathrm{~N}$ mit dem Koth $\frac{-\quad \text { IV }-3-3 \quad 83,975--\quad-1,29--\quad-\quad-}{\text { also an } 6 \text { Tagen } 166,835 \mathrm{~N} \text { mit dem Harn, 2,744 N mit dem Koth }}$ oder im Durehsehnitt täglich 27,806 - _ _ 0,457 -

macht zusammen 28,263 N. Die Differenz in der N-Ausscheidung $\mathrm{zwischen}$ den Perioden der Fett- und denen der Fettsäurefütterung liegt unterhalb $1 \mathrm{pCt}$, also innerhalb der unvermeidlichen Fehlergrenzen. Somit führt diese Fütterungsreibe zum Ergebniss, dass an den Verhältnissen der bestehenden Eiweisszersetzung nichts geändert wird, wenn statt des Fettes nur die in ihm enthaltenen (in Wasser unlöslichen) Fettsäuren verfüttert werden oder mit anderen Worten: Die Fettsäuren bewirken die gleiche Ersparniss im Eiweissverbrauch, wie die ihnen chemisch äquivalente Fettmenge.

Es galt nun dieses Resultat gegen jeden irgend begründeten Einwand zu sichern. Gegen die vorstehende Versuchsreibe konnte noch eventuell der Einwand erhoben werden, dass die Perioden, an welchen Fettsäturen gegeben wurden, zn kurze Zeit gedauert hätten, als dass sich erhebliche Modificationen in der Eiweisszersetzung hätten geltend machen können und dies um so mehr, als unmittelbar darauf wieder eine Periode mit Verabreichung von Fett folgte, durch welche die in Folge der voraufgegangenen Fütterung mit Fettsäuren etwa bedingten Stoffwechselalterationen wieder ausgeglichen wurden. Diese und ähnliche Einwände durften erst dann als widerlegt und gegenstandslos erachtet werden, wenn der Nachweis gelang, dass ein Hund, der bei einer Fiutterung mit Fleisch und Fett sich in $\mathrm{N}$-Gleichgewicht befand, also nur das verfütterte Eiweiss zersetzte, ohne von dem Eiweissbestande seines Körpers 
zuzusetzen, auch in N-Gleichgewicht beharrt, wenn Wochen hindurch statt des Nahrungsfettes nur die darin enthaltenen Fettsäuren gegeben wurden. Das Versuchsergebniss musste ferner um so beweisender ausfallen, je grösser der betreffende Organismus war, der zur Durchführung dieser Versucbsreihe gewäblt wurde, je geringer die Fleisch- und je grösser die Fettmengen waren, mit denen $\mathrm{N}$-Gleichgewicht erreicht wurde. Von solchen Gesichtspunkten aus wurde mit einer dressirten, grossen Hündin, deren Körpergewicht uiber 30 Kilo betrug, eine längere Versuchsreihe angestellt. Nach einer längeren Vorfütterung gelang es diesen Hund mit nur $600 \mathrm{Grm}$. Fleisch und $100 \mathrm{Grm}$. Fett in N-Gleichgewicht und auch annähernd in Körpergleichgewicht $\mathbf{z u}$ bringen. Nachdem dieser Zustand von N-Gleichgewicht auf Grund der Bestimmung der N-Ausscheidungen durch 5 Tage hindurch genügend constatirt war, wurden durch 21 Tage statt des Fettes je die aus 100 Grm. darstellbaren Fettsäuren verfüttert. Die N-Ausscheidung durch den Harn, sowie das Körpergewicht wurdè an allen 21 Tagen festgestellt, die Bestimmung des $\mathrm{N}$-Gehalts der Fäces geschah vur für die ersten und letzten 5 Tage. Schliesslich wurde 5 Tage lang wieder, wie in der Vorperiode, Fett gereicht. Die einzelnen, für die Beurtheilung der Stoffwechselverhältnisse in Betracht zu ziehenden Werthe sind in umstehender Tabelle verzeichnet.

In den 5 Tagen der Vorperiode wurde bei Fettfüterung ausgeschieden im Ganzen 100,296 N mit dem Harn und 2,11 $\mathrm{N}$ mit dem Koth, oder im Durchschnitt täglich $20,06+0,42 \mathrm{~N}$, macht $20,48 \mathrm{~N}$. An $\mathrm{N}$ wurde mit $600 \mathrm{Grm}$. Pferdetleisch eingeführt $20,4 \mathrm{~N}$, somit bestand genau N-Gleicbgewicht; daneben bestand auch annähernd Körpergleichgewicht, da das Gewicht des Thieres in den letzten 3 Tagen nur $z$ wischen 30,8 und 30,9 Kilo schwankte. An den 21 Tagen, an denen statt des Fettes nur die Fettsäuren gegeben wurden, entleerte der Hund in toto mit dem Harn $407,904 \mathrm{~N}$ oder täglich im Mittel 19,424 N. Mit dem Koth wurden ausgestossen an den ersten 5 Tagen dieser Periode $2,8 \mathrm{~N}$, in den letzten 5 Tagen $2,19 \mathrm{~N}$, also zusammen in 10 Tagen $4,99 \mathrm{~N}$ oder im täglichen Mittel $0,499 \mathrm{~N}$. Somit ergiebt sich als Durchschnittswerth für die tägliche Gesammtausscheidung während der Fettsäureperiode: $19,424+0,499=19,923 \mathrm{~N}$. Danach würde durch die Verabreichung der Fettsäuren sogar noch ejne gering- 
Grosser Hofhund. $600 \mathrm{Grm}$. Fleisch, $350-400 \mathrm{Ccm}$. Wasser.

\begin{tabular}{|c|c|c|c|c|c|}
\hline Datum. & Verfuttert. & $\begin{array}{l}\text { Harnmenge } \\
\text { in } \mathrm{Gcm} \text {. }\end{array}$ & $\mathrm{N}$ im Harn. & $\mathrm{N}$ im Koth. & $\begin{array}{l}\text { Körperge- } \\
\text { wicht in Kilo. }\end{array}$ \\
\hline 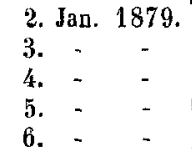 & $\begin{array}{c}\text { je } 100 \mathrm{Grm} . \\
\text { Fett }\end{array}$ & $\begin{array}{l}573 \\
578 \\
554 \\
456 \\
487\end{array}$ & $\begin{array}{l}19,992 \\
20,216 \\
20,328 \\
18,872 \\
20,888\end{array}$ & $\left.2,11^{1}\right)$ & $\begin{array}{l}31,08 \\
30,95 \\
30,8 \\
30,75 \\
30,89\end{array}$ \\
\hline $\begin{array}{rrr}7 . & - & - \\
8 . & - & - \\
9 . & - & - \\
10 . & - & - \\
11 . & - & - \\
12 . & - & - \\
13 . & - & - \\
14 . & - & - \\
15 . & - & - \\
16 . & - & - \\
17 . & - & - \\
18 . & - & - \\
19 . & - & - \\
20 . & - & - \\
21 . & - & - \\
22 . & - & - \\
23 . & - & - \\
24 . & - & - \\
25 . & - & - \\
26 . & - & - \\
27 . & - & -\end{array}$ & $\begin{array}{c}\text { Fettsäuren } \\
\text { aus je } \\
100 \mathrm{Grm} \text {. Fett }\end{array}$ & $\begin{array}{l}484 \\
\mathbf{5 0 3} \\
499 \\
566 \\
607 \\
552 \\
507 \\
484 \\
481 \\
469 \\
455 \\
439 \\
451 \\
460 \\
538 \\
437 \\
446 \\
470 \\
481 \\
497(?) \\
495\end{array}$ & $\begin{array}{l}19,88 \\
20,02 \\
19,768 \\
20,272 \\
20,468 \\
21,448 \\
20,888 \\
19,264 \\
18,676 \\
19,096 \\
19,432 \\
18,704 \\
18,592 \\
19,068 \\
18,508 \\
18,956 \\
19,516 \\
18,872 \\
18,396 \\
19,404 \\
18,676\end{array}$ & $\left.2,19^{3}\right)$ & $\begin{array}{l}30,84 \\
30,81 \\
30,82 \\
\mathbf{3 0 , 7 6} \\
30,7 \\
30,65 \\
30,64 \\
30,65 \\
30,42 \\
30,4 \\
30,27 \\
30,4 \\
30,42 \\
30,59 \\
30,44 \\
30,57 \\
30,65 \\
30,69 \\
\mathbf{3 0 , 7 9} \\
30,74 \\
30,85\end{array}$ \\
\hline 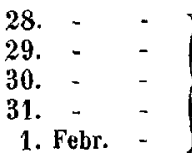 & $\begin{array}{c}\text { je } 100 \mathrm{Grm} . \\
\text { Fett }\end{array}$ & $\begin{array}{l}514(?) \\
559 \\
633 \\
567 \\
594\end{array}$ & $\begin{array}{l}19,32 \\
21,028 \\
22,148 \\
21,728 \\
21,952\end{array}$ & $\left.2,003^{4}\right\}$ & $\begin{array}{l}30,88 \\
30,84 \\
\mathbf{3 0 , 7 9} \\
\mathbf{3 0 , 6 9} \\
\mathbf{3 0 , 5 1}\end{array}$ \\
\hline
\end{tabular}

fügige Ersparniss im Eiweissverbrauch bewirkt worden sein, auf die indess - sie beträgt nur 2 pCt. - kein Werth zu legen ist. Auf Grund dieser mehrwöchentlichen Fütterungsreibe darf jedenfalls so viel behauptet werden, dass die Eiweisszersetzung im Körper des Fleischfressers ungeändert bleibt, gleichviel ob Fett oder nur die äquivalente Fettsäuremenge verfüttert wird. Erwägen wir ferner, dass auch das Körpergewicht des Thieres nach dreiwöchentlicher

1) Trockengewicht des Koths $41,8 \mathrm{Grm}$. mit $5,05 \mathrm{pCt}$. N,

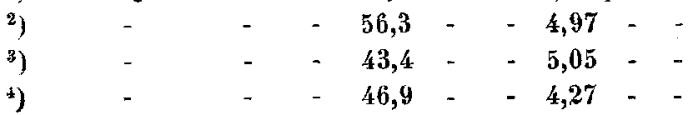


Fettsäurefütterung gegenüber dem in der Vorperiode bestandenen keine wesentliche Differenz zeigt, so führt die Versuchsreihe zu dem böchst bemerkenswerthen Schluss, dass ein Hund, der mit einem Futter aus Fjeisch und Fett in $\mathrm{N}$ - und Körpergleichgewicht sich befindet, im Gleichgewicht verhart, auch wenn 21 Tage hindurch statt des Fettes nur die in letzlerem enthaltenen Fettsäuren gegeben werden; es kommt also den Fettsäuren die gleiche Bedeutung als Sparmittel zu, wie dem Fett.

Was die Ausnützung der gefütterten Fettsäuren im Darm betrifft, so ist zunächst daran zu erinnern, dass schon bei mässiger Fettaufnahme der Koth Kalk- und Magnesiaseifen neben Resten von Neutralfett enthält. Nach Einführung von Fettsäuren durften wir nach den oben erwähnten Erfahrungen für den Fall, dass ein Theil der verfülterten Fettsäuren im Darme nicht zur Ausnutzung gelangte, neben einer vielleicht vermehrten Menge von Seifen noch freie Fettsäuren antreffen, ist $j a$ auch der Gehalt des Koths an Alkalien und Erden nicht so hoch, dass von ihnen erbebliche Mengen freier Säuren gebunden werden könnten. Zur quantitativen Bestimmung des Gehalts der Fäces an Fett resp. freien Fettsäuren wurde in der Weise verfahren, dass wir den auf dem Wasserbade sorgfältig getrockneten Koth fein pulverisirten und gewogene Mengen davon wiederholt mit warmem Aether extrahirten, so lange dieser noch etwas aufnahm. Die filtrirten und vereinigten gelbgefärbten Aetherauszüge konnten Fett, freie Fettsäuren, Lecithin, Cholestearin und etwas Gallenfarbstoff enthalten. Zur Bestimmung der freien FeltSäuren wurde nun nach dem Vorgange von Franz Hofmann ${ }^{\text {) }}$ der Aetherextract mit einigen Tropfen einer alkoholischen Lösung von Rosolsäure versetzt und nun alkoholische Zehntelnormalnatronlösung ${ }^{2}$ ) aus einer Bürette vorsichtig zugelassen, bis dass die Reaction eben alkalisch wurde, ein Punkt, der sich durch Eintritt der rothen Färbung deutlich markirt. Von anderen, in den Fäces vorbandenen fetten flüchtigen Säuren, wie Essigsäure, Butter- und

1) Ueber die Reaction der Fette und die quantitative Bestimmung der Fettsäuren in Fetten. Beiträge z. Anat. 17. Physiol. als Festgabe Carl Ludwig gewidmet. I. 1874. S. 134 .

2) Zar Bereitung derselben wurde $1 \mathrm{Th}$. Normalnatronlösung wit 2 Th. Wasser und $7 \mathrm{Th}$. absol. Alkohol versetzt. 
Isobuttersäure, Baldrian- und Capronsäure, die ebenfalls in den Aether übergehen würden, ist bisher nur von der Buttersäure dargethan, dass sie in freiem Zustand im Koth vorkommt, die übrigen werden in der Regel erst bei Destillation der (mit Wasser angerührten) Fäces mit verdünnter Schwefelsäure erhalten ${ }^{1}$ ). Ueberdies mussten die vorerwähnten, in den Fäces etwa in freiem Zustande vorhandenen, niederen Fettsäuren bei dem der Aetherextraction vorangehenden Trocknen der Fäces zum grossen Theil sich verflüchtigen. Um jedoch über die Grösse des noch restirenden Antheils freier niederer Fettsäuren in den der Aetherbebandlung unterworfenen Fäces der Fettsäurefütterungstage eine Vorstellung zu gewinnen, wurden von dem trockenen und pulverisirten Koth, der auf die Fettsäurefütterung beim letztangeführten Versuche entfiel und der für 5 Tage (7.-11. Januar 1879) im trocknen Zustande 56,3 Grm. wog, $15 \mathrm{Grm}$. mit viel Wasser angerührt und ohne weiteren Zusatz destillirt. Das neben fetten Säuren reichlich Ammoniak enthaltende Destillat mit verdünnter Schwefelsäure im Ueberschuss versetzt und abermals destillirt. Das so rectificirte Destillat, mit Rosolsäure versetzt und mit einer alkoholischen Zehntellauge titrirt, ergab einen Gehalt an niederen Fettsäuren, gleich 9,7 Gcm. Zehntelsäure oder auf Buttersäure berechnet $(1 \mathrm{Ccm}$. Normallauge entspricht $0,088 \mathrm{Grm}$. Buttersäure) $=0,085 \mathrm{Grm}$. Für den Gesammtkoth der 5 Feltsäuretage $(56,3 \mathrm{Grm}$.) ergeben sich so $0,306 \mathrm{Grm}$. als die nach dem Trocknen noch im Koth vorhandenen Buttersäuremengen oder per Tag 0,061 Grm. Buttersäure. Eine andere Bestimmung in dem Koth der Fettsäureperiode vom 23. bis 27. Januar 1879 (Gesammtmenge $43,4 \mathrm{Grm}$.) ergab in $9 \mathrm{Grm}$. Trockenkoth flüchtige Säuren, entsprechend $8,4 \mathrm{Ccm}$. Zehntelsäure $=0,074$ Grm. Buttersäure, also auf die Gesammtmenge von 43,4 Grm. berechnet, $0,357 \mathrm{Grm}$. oder auf den Tag 0,071 Grm. Buttersäure. - Dem gegenüber fanden sich in $10 \mathrm{Grm}$. trockner Fäces von der Fettperiode desselben Versuches (2.-6. Januar; Gesammtmenge 41,8 Grm.) flüchtige Säuren entsprechend 5,2 Ccm. Zehntelsäure $=0,046 \mathrm{Grm}$. Buttersäure, also für den Gesammtkoth $0,193 \mathrm{Grm}$. oder für den Tag $0,039 \mathrm{Grm}$. Buttersäure. Ferner

1) L. Brieger, Die flüchtigen Bestandtheile der Exeremente. Journ. f. pract. Chemie. N. F. XVII. S. $124 \mathrm{ff}$. 
in 12,3 Grm. Trockenkoth der Fettperiode rom 28. Januar bis 2. Februar (Gesammtmenge 46,9 Grm.) flüchtige Säuren entsprechend $8,6 \mathrm{Ccm}$. Zehntelsäure $=0,076 \mathrm{Grm}$. Buttersäure, also für den Gesammtkoth $0,356 \mathrm{Grm}$. oder täglich $0,071 \mathrm{Grm}$. Buttersäure. Mithin sind, was die flüchtigen Fettsäuren anlangt, im Koth nach Fett- resp. Fettsäurefütterung keine so erheblichen Differenzen vorhanden, dass der Gehalt an flïchtigen Fettsäuren für die Titrirung des Aetherextracts einen sonderlichen Fehler bedingen könnte.

8,226 Grm. des Trockenkoths von der Fettperiode I der ersten Versuchsreihe (S. 17) ergaben im Aetherextract fette Säuren entsprechend 17,8 Ccm. Zehntelsäure, also für den Gesammtkoth von 32,4 Grm. einen Gehalt an Fettsäuren entsprechend 70,1 $\mathrm{Ccm}$. Zebntelsäure. Auf Palmitinsäure $(1 \mathrm{Gcm}$. Zehntelsäure $=0,0256 \mathrm{Grm}$. Palmitinsäure) herechnet, stellt sich danach der Gesammtgehalt an Palmitinsäure auf $1,794 \mathrm{Grm}$.

6,796 Grm. Trockenkoth von der Fettsäureperiode II derselben Versuchsreihe enthielten an Fettsäuren ein Quantum, das 15,9 Ccm. Zehntelsäure, also für die ganze Menge von 31,15 Grm. Koth: $7,29 \mathrm{Ccm}$. Zehntelsäure entsprach $=1,866 \mathrm{Grm}$. Paimitinsäure.

Für eine fernere Fettsäureperiode (Per. IV) der nehmlichen Versuchsreihe fand sich in $8,82 \mathrm{Grm}$. Trockenkoth ein Gehalt an Fettsäuren entsprechend $22,1 \mathrm{Ccm}$. Zehntelsäure, also berechnen sich für den Gesammtkoth (29,6 Grm.) 74,3 Ccm. Zehntelsäure $=1,902 \mathrm{Grm}$. Palmitinsäure.

Es ist somit bei Fütterung mit Fettsäuren (bis 100 Grm. fưr den Tag) der Gehalt der Fäces an freien Fettsäuren nur wenig höher, als bei Darreichung von Fett, nehmlich nur um $4-6$ pCt. Daraus folgt, dass vou einem erheblichen Abgange der verfütterten Fettsäuren mit dem Koth nicht entfernt die Rede sein kann.

Endlich ist noch die Frage zu ventiliren, ob nicht bei Fettsäurefütterung die normal im Koth gefundenen Kalk- und Magnesiaseifen eine beträchtliche Vermebrung zeigen. Zur Untersuchung auf Seifen wurde der von der Fett- und Fettsäureextraction hinterbliebene Rückstand des Trockenkoths mit Salzsäure angesäuert und nunmehr mit Aether ausgeschüttelt. Bei der Extraction mit saurem Aether gehen beträchtliche Mengen vom braunen Farbstoff der Fäces, den Abkömmlingen des Gallenfarbstoffs, mit in den Auszug über 
und sind daraus auf einfachem Wege nicht abzuscheiden. Es ist somit die Bestimmung der Seifen im Koth stets mit dem Fehler behaftet, dass gleichzeitig ein nicht unerheblicher Theil des Farbstoffs mitgewogen wird, wodurch die Resultale zu hoch ausfallen müssen. Ein quantitativer Vergleich des Seifengehalts der Fäces nach Verfütterung von Schweinefett mit dem nach Darreichung der Säuren des Schweinefetts ergab keine sehr auffälligen Unterschiede. Der nach der Extraction mit Aether hinterbliebene Rückstand von den 8,226 Grm. Trockenkoth (der Fettperiode I der ersten Versucbsreihe) gab an sauren Aether ab: 0,405 Grm., Seifen (als Fettsäuren gewogen) + Farbstoff, also für die Gesammtmenge von 32,4 Grm. berechnet: 1,595 Grm. - Von der Fettsäureperiode I derselben Versuchsreihe gaben die 6,796 Grm. bereits mit Aether erschöpften Trockenkoths noch an sauren Aether ab: 0,393 Grm. Seifen + Farbstoff and für die Gesammtmenge von $31,15 \mathrm{Grm}$. Koth berechnet: 1,801 Grm. Es werden also nach Einverleibung von Fettăuren nur unerheblich mehr Seifen mit dem Koth a usgeschieden, als nach Einfuhrung der gleichen Fettmenge.

Bei der nunmehr festgestellten Gleichwerthigkeit des Fettes und der Fettsäuren für die dadurch gesetzte Ersparniss im Eiweissverbranch dïrfte es von besonderem Interesse sein, die Schicksale der Fettsäuren nach ihrem Uebertritt aus der Darmhöhle in die Säfte genauer zu verfolgen. Tödtet man einen Hund einige Stunden nachdem man ihm Fettsäuren verabreicht hat, so findet man die Chylusgefässe des Mesenterium mit einem milchweissen Inhalt prall erfüllt, nicht anders als dies bei einem fettverdauenden Hund der Fall ist. Diese Erscheinung war für mich so überraschend, dass es mir doppelt geboten erschien, nachzusehen, ob bei der von mir befolgten, oben beschriebenen Methode der Darstellung von Fettsäuren aus Fett durch Verseifung des letzteren und Zersetzung der gebildeten Seifen durch Säureüberschuss, nicht erbebliche Antheile von Fett sich dem Verseifungsprozess entziehen. Zur Prüfung auf etwa noch unverseiftes Fett wurden $50 \mathrm{Grm}$. Fett mit $30 \mathrm{Ccm}$. concentrirter Natronlauge (spec. Gew. 1,34) 2 Stunden lang gekocht, der Seifenleim noch warm mit Wasser versetzt, bis das Volumen der Seifenlösung $800 \mathrm{Ccm}$. betrug. Von dieser Lösung wurden $50 \mathrm{Ccm}$. zur Bestimmung des etwa noch vorhandenen un- 
verseiften Fettes mit Aether wiederholt ausgeschüttelt, von der vereinigten ätherischen Lösung der Aether abdestillirt und der geringe, aus kleinen gelblichen Oeltröpfchen bestehende Inhalt unter der Luftpumpe bis zu constantem Gewicht getrocknet. Der Rückstand erstarrte zu einer weisslichen, fettig aussehenden und sich anfühlenden Masse, er wog $0,041 \mathrm{Grm}$., somit waren in der gesammten Seifenlösung: $16 \times 0,041=0,656 \mathrm{Grm}$. Fett, die bei der Verseifung von $50 \mathrm{Grm}$. Felt unangegriffen blieben. Es entzogen sich also bei nur 2 stündigem Kochen mit Natronlauge der Verseifung 1,312 pCt. Fett. Ein ebenso angestellter Versuch, bei dem indessen, wie bei meinen Darstellungen der Fettsäuren üblich, 3 Stunden lang mit der Lauge gekocht wurde, ergab nur 1,07 pCt. Fett noch unverseift. Wahrscheinlich ist jedoch die Menge des der Verseifung entgangenen Fettes geringer, als die bei der Aetherextraction erhaltenen Werthe anzeigen. Kühn ${ }^{1}$ ) hat meines Wissens zuerst die Aufmerksamkeit darauf gelenkt, dass es nicht gelingt, aus einer Seife enthaltenden Lösung mit Aether resp. Petroleumäther, selbst bei Wiederholung des Verfahrens, von Seife ganz treie Extracte zu erhalten. Es müssen demnach bei der Gewichtsbestimmung des Aetherextracts die Werthe durch mitaufgenommene Antheile von Seife stets etwas zu hoch ausfallen.

Nach dem, was oben über den Modus der Emulgirung fetter Säuren beigebracht worden ist, konnte das milchige Aussehen des Chylus einfach durch freie Fettsäuren bedingt sein, die neben den normal vorkommenden, geringen Mengen von Neutralfett darin emulgirt sind. Dass hierüber nur die chemische Analyse des Chylus entscheiden kann, ist bereits oben dargethan worden.

Ueber die Fettverdauung und die hierbei stattfindenden Verhältnisse des Fettgehalts vom Chylus haben die in C. Ludwig's Laboratorium angestellten Untersuchungen von $\mathrm{Zawilski}{ }^{2}$ ) unsere diesbezüglichen Kenntnisse wesentlich erweitert. Zawilski hat gefunden, dass nach einer reichlichen Fettfütterung die Zufubr des resorbirten Fettes durch den Chylus in's Blut ziemlich 30 Stunden lang dauert; in der 30. Stunde nach der Fettfütterung ergiessen sich durch den Milchbrustgang pro Stunde nur noch 0,06 Grm.

1) Kühne und Ayres, Ueber lichtbestanndige Farben der Netzbaut. Untersuch. a. d. physiol. Instit. zu Heidelberg. I. Heft 4.

2) Arbeiten aus d. physiol. Anstalt zu Leipzig. XI. S. 1 $47-167$. 
Fett, also ungefahr so viel Fett, als den Brustgang im Hungerzustande durchströmt. Schon in der 2. Stunde nach der Fettfütterung ist die Fettströmung durch den Brustgang im Gange, gelangt gegen die 5. Stunde zu ihrer grössten Stärke; auf dieser erhält sie sich, wenn auch unter Schwankungen, bis gegen die 20. Stunde und sinkt von da ab allmählich herunter, um in der 30 . Stunde zu erlöschen.

Bei den vielfachen Analogien zwischen dem Fett und den Fettsäuren war zu erwarten, dass auch ähnliche Verhältnisse für die Resorption der Fettsäuren gelten werden. Die Aufgabe, die ich mir nunmehr stellte, war zu untersuchen, wie sich der Chylus eines Thieres bei Verdauung von Fettsäuren in Bezug anf die darin enthaltenen Fettkörper und zwar Neutralfett, etwaige fette Säuren und Seifen quantitativ verhält. Der Fettstrom durch den Brustgang ist nach Zawilski von der 6 . Stunde ab am lebhaftesten. Von diesem Zeitpunkte anfangend, sollte auch der Chylus von Thieren bei Fettsäureverdauung aufgefangen und sein Gehalt an Fettkörpern bestimmt werden. $\mathrm{Zu}$ diesen Versuchen wurden grosse Hunde von 20 bis 38 Kilo gewahlt, ihnen zu einer bestimmten Zeit nach der Fütterung der Fettsäuren in tiefer Morphiumnarcose der Ductus thoracicus am Halse freigelegt und unmittelbar vor seiner Einmündung in den Vereinigungswinkel der V. subclavia und jugularis com. sin. eine Glascanüle eingebunden. Die Operation ist, wofern man zunächst dem inneren Rande der Jugularis folgt und sich weiter unten an der hinteren Wand der Vene hält, nicht gerade schwer auszuführen. Man sieht dann uber der oberen Brustapertur an der äusseren Seite der Carotis den Brustgang schief und zuweilen in einem Bogen nach vorn gegen den Bildungswinkel der V. jugul. und subclavia ziehen, kann ihn hier in einer Länge von mehreren Centimetern freilegen und nach vorgängiger Unterbindung eine Canüle in ihn einbinden. Zuweilen ergiesst sich kurz vor seiner Einmündung in ihn der linke grosse Halslymphstamm; diesen klemmt man, da es ja hier sich nur darum handelt, den Chylus aufufangen, zweckmässiger Weise ab; man kann so, wenn nicht Gerinnungen eintreten, in reichlicher Menge Chylus gewinnen. Kleinere Gerinnsel in der Canüle entfernt man durch vorsichtige Sondirung mit einer feinen Federfahne oder einem Draht; doch gelingt es ab und zu nicht, die Gerinnsel flott zu machen; es ist dann der Versuch als missglückt aufzugeben. Da es für die weitere, chemische 
Untersuchung gerade darauf ankommt, an der normalen Zusammensetzung des strömenden Chylus nichts zu ändern, so ist es selbstverständlich nicht gestattet, etwa durch Einfübrung fibrinlösender Substanzen, z. B. kohlensaurer Alkalien, die Gerinnung zu verhindern.

Zunächst sucbte ich festzustellen, wie viel Fett normal mit der Darmlymphe, dem Chylus hungernder oder nur Eiweiss verdauender Thiere in einer bestimmten Zeit, z. B. einer Stunde durch den Ductus thoracieus strömt. Wie schon angeführt, hatte Zawilski gefunden, dass bei seinem Hunde von etwa 13 Kilo 30 Stunden nach der Fülterung 0,06 Grm. Fett durch den Brustgang hindurchgeht; da um diese Zeit nach seinen Erfahrungen die Fettverdauung als vollständig beendet anzusehen ist, so dürfte es wahrscheinlich sein, dass jener Werth $(0,06 \mathrm{Grm}$. Fett pro Stunde) ungefähr auch die Fettmenge repräsentirt, welche durch den Brustgang hungernder oder nur eiweissverdauender Thiere hindurchgeht. Zur Feststellung đieses Verhältnisses wurde ein Hund von 34 Kilo, der nach 36 stündigem Hungern $300 \mathrm{Grm}$. mageres Pferdefleisch bekommen hatte, in der 6 . Verdauungsstunde aufgebunden, der Ductus thoracicus freigelegt und mit einer Canüle armirt. Die 7. Verdauungsstunde hindurch wird der Chylus aufgefangen; dieser, von bläulich weisser Opalescenz, gerann im Sammelgefäss leicht und schnell, der Kuchen nahm eine röthliche Farbe an, wie dies bei Chylus in der Regel der Fall ist. Es liessen sich während einer Stunde - wegen der grossen Neigung zum Gerinnen wurde der Ausfluss von Zeit zu Zeit durch Pumpbewegungen mit einem Hinterbein unterstützt $-48 \mathrm{Ccm}$. Chylus (spec. Gew. 1026) gewinnen.

Zur Bestimmung des Fettes wurde der Chylus wiederholt mit Aether ausgeschüttelt, die ätherische Lösung abgegossen und abfiltrirt, der Aether abdestillirt und der Aetherextractrückstand in einem kleinen Becherglase unter der Luftpumpe neben Schwefelsäure getrocknet. Der bis zu constantem Gewicht getrocknete Rückstand wog 0,126 Grm., es waren also durch den Chylus des eiweissverdauenden Hundes in einer Stunde (7. Stunde nach der Mahlzeit) 0,126 Grm. Fett geströmt. Da aber der Aether zugleich mit dem Fett auch Lecithin und Cholestearin aufnimmt, die hier, ebenso wie in den Bestimmungen von Zawilski, mit als Felt in Rechnung gezogen sind, so duirfte bei Zugrundelegung einer Analyse von 
Hoppe-Seyle ${ }^{1}$ ), der bei Trennung der im Aetherauszuge des Cbylus enthaltenen Körper etwa $\frac{1}{\gamma}$ davon aus Cholestearin und etwa $\frac{1}{1^{2}}$ aus Lecithin bestehend ( fand $^{2}$ ), die Fettmenge, die durcb den Chylus eines grossen Hundes bei reiner Eiweissverdaung innerhalb 1 Stunde dem Blute zugeführt wird, ungefähr nur $0,1 \mathrm{Grm}$. betragen, ein Werth, der mit dem von Zawilski bei seinem, nur 13 Kilo schweren Hunde gefundenen $(0,06 \mathrm{Grm}$. Fett) gut harmonirt. Nach dem Erschöpfen mit Aether wurde der Chylus mit Schwefelsäure angesäuert, wobei eine reichliche Fällung von Albuminaten entstand, so aus den Seifen die Fettsäuren frei gemacht und diese letzteren durch wiederholtes Ausschütteln mit Aether extrahirt. Es wurde so an Fettsäuren, die als Seifen präformirt vorhanden waren, $0,1475 \mathrm{Grm}$. gefunden (Versuch 1).

Die Versuche mit Einführung von Fettsäuren geschahen in der Regel in der Weise, dass Hunden, die mindestens 36 Stunden gehungert hatten, $300 \mathrm{Grm}$. mageres Pferdefleisch und in der durch Abkochen desselben mit $200 \mathrm{Ccm}$. Wasser hergestellten Fleischbrühe die Fettsäuren, die bei $30^{\circ}$ darin butterweiche Consistenz annehmen, gegeben wurden. In dieser Form wurden die Fettsäuren, wie erwähnt, bis auf einen Fall von den Thieren ohne Widerwillen genommen. Einem Hund von etwa 18 Kilo, der dieses Futtergemisch verschmähte, wurde in der Narcose durch eine kleine Bauchwunde eine Dünndarmschlinge hervorgeholt - dieselbe war, dem Hungerzustande entsprechend, blass, zusammergezogen, auf dem zugehörigen Mesernterium war von Injection der Chylusgefässe absolut nichts zu entdecken - und in diese direct ca. $50 \mathrm{Grm}$. Fettsäuren eingespritzt,

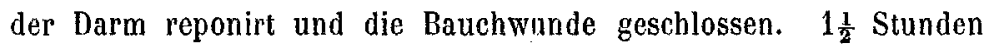
später wurde in den Ductus thorac. eine Canüle eingeführt und der ausströmende Chylus die ganze 3. Verdauungsstunde hindurch aufgefangen. Der Chylus sab wie verdünnte Milch aus. Es wurden im Ganzen $37 \mathrm{Ccm}$, aufgefangen. Als dann der Hund mit Blausäure getödtet wurde, fand man die Chylusgefässe des Mesenterium schön milchweiss gefüllt, im Dünndarm eine nicht sehr beträchtliche Menge eines gelben, schleimig-fetten Inhalts.

1) Physiologische Chemie. III. Berlin 1879. S. 597.

2) Ich selbst babe bei Trennung des Aetherauszuges vom fettreichen Chylus verdauender Hunde in zwei später zu erwähnenden Versuchen etwa $\frac{1}{12}$ bis ito davon aus Cholestearin bestehend gefunden. 
Die Untersuchung des Chylus nach Fettsäurefütterung wurde zur Trennung des Fettes und der Seifen von etwa vorhandenen freien Fettsäuren so ausgefübrt: Zunächst wurde die ganze einstündige Menge oder ein aliquoter Theil davon mit Aether erschöpft; in diesen gehen Fett, freie Fettsäuren, Cholestearin und Lecithin über. Der nach Abdestilliren des Aether hinterbleibende Rückstand wurde behufs Trennung des Fettes von freien Fettsäuren nach HoppeSeyler's Empfehlung mit starker Sodalösung gekocht, dadurch die Fettsäuren verseift, während das Fett und Cholestearin unangegriffen bleiben; gleichzeitig wird dadurch das Lecithin zersetzt. Aus dieser Seifenlösung wurde nun das Fett nebst Cholestearin mittelst Aether ausgezogen und der Aetherextractrückstand nach dem Trocknen gewogen ${ }^{1}$ ). Weiter wurden aus der Seifenlösung durch Ansäuern mit Schwefelsäure die Fettsäuren wieder regenerirt und nun ihrerseits in ätherische Lösung übergeführt und ihr Gewicht bestimmt.

Endlich wurde noch der durch den Aether vom Fett und den Fettsäuren befreite, aber noch die Seifen enthaltende Chylus angesăuert und die so aus den präformirten Seifen freigewordenen Fettsäuren gleichfalls mit Aether extrahirt, im Vacuum getrocknet und als Fettsäuren gewogen.

Nach dieser Methode fand ich in dem, während der 3. Stunde nach directer Einspritzung der Fettsäuren in den Dünndarm aufgesammelten Ghylus:

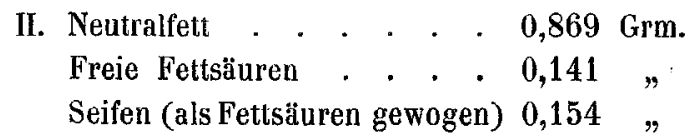

Schon dieses Resultat ist in mehreren Beziehungen interessant.

1) Will man das Cholestearin vom Fett trennen, so verseift man den Rückstand und extrahirt aus der Seifenlösung das Cholestearin mittelst Aether. In zwei so ausgeführten Bestimmungen ergab sich: (Vers. III) Neutralfett + Cholestearin 2,332 Grm., davon Cholestearin 0,238 Grm. Ferner, (Vers. VII) Neutralfett + Cholestearin 1,319 Grm., davon $0,1105 \mathrm{Grm}$. Cholestearin; also besteht ein Zwölftel bis ein Zehntel des als Neutralfett gewogenen Rückstandes aus Cholestearin. Wie bereits erwähnt (S. 25), muss auch die Menge des durch den Aether aufgenommenen Cholestearin durch gleichzeitig in den Aether übergehende Antheile von Seife stets etwas zu hoch ausfallen. Uebrigens wurde aus dem Aetherextractrückstand durch Umkrystallisiren aus Chloroform und durch die Jod-Schwefelsäure-Reaction das Cholestearin als solches festgestelit. 
Zunächst ist das Vorkommen freier Fettsäuren neben Fett in ChyIus nacb Fettsäurefütterung böchst beachtenswerth; die Fettsäuren krystallisirten aus der ätherischen Lösung in schönen langen Nadeln. Ihr Vorkommen im Chylus ist nur von dem Gesichtspunkte aus zu verstehen, den wir oben bezüglich der Emulgirung freier Fettsäuren durch alkalische, Eiweiss resp. Seifen gelöst enthaltende Flüssigkeiten beleuchtet haben. An Neutralfett fand jch etwa 14 Mal so viel, als durch den Chylus eines hungernden (Zawilski) uud über $7 \mathrm{Mal}$ so viel, als durch den Brustgang eines nur mit Eiweiss gefütterten Hundes in einer Stunde hindurchströmt. Nach den Erfahrungen von Zawilski, denen zufolge die Fettströmung durch den Brustgang erst etwa in der 6. Stunde zu ihrer grössten Stärke gelangt, stand zu erwarten, dass die Resultate noch beweisender ausfallen würden, falls das Aufsammeln des Chylus nach Fettsäurefütterung erst von der 6 . Stunde ab erfolgte. Zudem konnte in dem eben erwähnten Versuche die dabei vorgenommenen Manipulationen, das Oeffnen der Bauchböhle, Herausholen einer Darmschlinge, Injection der Fettsäuren in diese, endlich die stundenlange Fesselıng, nur ungünstig auf den Verdauungsprozess einwirken und auch die Resorption wesentlich beeinträchtigen. In der That hat es sich vortheilhafter erwiesen, den Thieren die Fettsäuren mit dem Futter beizubringen, sie erst in einer späteren Zeit der Verdauung, wenn die Resorption im lebhaftesten Gange ist, also nicht vor Ende der 5. Stunde aufubinden und erst dann den Chylus aufufangen. Von dergleichen gelungenen Versuchen seien angeführt:

1II. Hund von fast $38 \mathrm{Kilo,} \mathrm{mit} 300 \mathrm{Grm}$. Fleisch und den Fettsäuren von $100 \mathrm{Grm}$. Fett gefüttert. Chylus aufgefangen während der 6 . und 7 . Verdauungsstunde. Es fanden sich, auf die einstündige Chylusmenge berechnet:

Neutralfett $\cdot \cdot 2,332 \mathrm{Grm} .{ }^{1}$ )
Freie Fettsäuren $\cdot 0,415-$
Fettsäuren als Seifen $0,175-$

IV. Hund von $21 \mathrm{Kilo,}$ erhält gleichfalls $300 \mathrm{Grm}$. Fleisch und die Fettsäuren von $100 \mathrm{Grm}$. Fett. 5 Stunden danach Morphium subeutan, er erbricht einen erhehlichen Theil des Verfütterten. Von der Mitte der 6. bis Mitte der 7. Stunde nach der Fütterung werden $51 \mathrm{Ccm}$. eines milehigen Ghylus (spec. Gew. = 1017) aufgefangen. Es ergab sich:

1) Die Verseifung ergab einen Gehalt an Cholestearin von 0,238 Grm. (s. die Anmerkung auf S.29), sodass sich danach der Werth für Neutralfett auf $2,094 \mathrm{Grm}$. erniedrigt. 
$\begin{array}{llll}\text { Neutralfett . . } & 1,01 & \text { Grm. } \\ \text { Freie Fettsäuren . . } & 0,071 & - \\ \text { Fettsäuren als Seifen } & 0,1655 & -\end{array}$

v. Grosser Hund, Fettsäuren von $120 \mathrm{Grm}$. Fett. Chylus aufgesammelt während der 11. Verdauungsstunde.

$\begin{array}{llll}\text { Neutralfett . . } & 1,7505 & \mathrm{Grm} . \\ \text { Freie Fettsäuren . . } & 0,101 & - \\ \text { Fettsäuren als Seifen } & 0,199 & -\end{array}$

Zur weiteren Sicherstellung des bisher gewonnenen Resultates wurden die nach dem Gange der Analyse als Neutralfett anzusehenden und als solches in Rechnung gestellten Rückstände des ersten Aetherextractes mit Bleioxydhydrat unter Zusatz von Wasser längere Zeit gekocht, von dem gebildeten Bleipflaster die wässerige Lösung abfiltrirt, zur Entfernung des darin gelösten Bleies Schwefelwasserstoff durch sie hindurchgeleitet und das Filtrat vom abgeschiedenen Schwefelblei eingedampft. Der geringe syrupöse Rückstand, der deutlich süss schmeckte, wurde in 2 Theile getheilt; der eine, mit Kupferlösung versetzt, hielt auch auf Zusatz von Aetzalkali Kupferoxyd mit schön blauer Farbe in Lösung; der andere mit saurem schwefelsaurem Kali im Ueberschuss vermischt und erhitzt gab den charakteristischen Acroleingeruch. Demnach enthielt der syrupöse Rückstand Glycerin. Nach dem Gange des eingeschlagenen Verfahrens musste somit das untersuchte Material aus Fett bestehen, aus dem durch Kochen mit Metalloxyd das nachgewiesene Glycerin abgespalten worden ist.

Endlich ist noch über zwei mit Oelsäure angestellte Versuche zu berichten. Käufliche Oelsäure, die sich nach Kochen mit Bleioxydbydrat in der ebenerwähnten Weise durchaus frei von Glycerin, also auch von jeder Fettbeimischung erwiesen hatte, wurde von den der Oelsäure häufig anhängenden niederen flüchtigen Fettsäuren durch wiederholtes Ausschütteln mit heissem Wasser möglichst gereinigt. Dieselbe wurde alsdann zu je 70-80 Grm. zu einer Abkochung von $300 \mathrm{Grm}$. mageren Fleisches hinzugefügt und da ein Vorversuch gezeigt, dass Hunde, selbst wenn sie mehrere Tage gehungert hatten, dieses Futter wegen des kratzenden und scharfen Geschmackes der 0elsäure verschmähten, mit 50-80 Grm. Rohrzucker versetzt. Das also versüsste Futtergemenge nahmen die Thiere, wenn auch offenbar mit einigem Widerwillen, doch vollständig auf. 
Vl. Grosser Hund wird 8 Stunden nach Aufnahme der 0elsäure mit Morphinm narcotisirt, woranf er einen beträchtlichen Theil des Futters wieder erbricht.

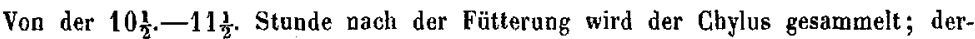
selbe sieht wie verdünnte Mileh aus und gerinnt im Sammelgefäss schnell zu einer etwas röthlichen Gallerte. Die Analyse des Cluylus ergiebt:

Neutralfett . . 0,917 Grm.
Freie Fettsäuren . . $0,026-$
Fettsäuren als Seifen $0,227 \quad-$

VII. Hund von 17,6 Kilo erhält nach 4tägigem Hungern $80 \mathrm{Grm}$. Oelsăure. In der 11. Stunde danach der Brustgang freigelegt and der Cbylus die ganze 12. Verdauungsstunde hindurch aufgefangen. Der Cbylus von milchweisser Farbe, etwa $40 \mathrm{Ccm}$, gerinnt aur langsam.

\begin{tabular}{|c|c|}
\hline fett & 1,319 \\
\hline Freie Fettsäuren & $0,15 \overline{5}$ \\
\hline Fettsäuren als Seifen & 0,1565 \\
\hline
\end{tabular}

Die Verseifung der ,1,319 Grm. Fett" ergab darin 0,1105 Grm. Cholestearin, also etwa den 12. Theil der als Neutralfett gewogenen Substanz. Wie schon erwähnt, fällt wegen der nicht absoluten Unlöslicbkeit der Seifen in Aether die Bestimmung des Cholestearingehaltes etwas zu hoch aus.

Nach Erstickung des Thieres durch Chloroform wurde der Magen am Pylorus abgebunden, ebenso der Dünndarm etwa 9 Zoll unter dem Pylorus und ferner an der Ileocöcalklappe. Im Magen fand sich noch ein erheblicher Antheil vom gefütterten Fleische in einer blutigen, braunröthlichen Flüssigkeit, in der grosse Oeltropfen umherschwammen. Eine Probe davon zeigte unter dem Mikroskope ausserordentlich grosse Fett- (Oelsäure-) Tropfen. In der abgeschnürten, oberen und kürzeren Partie des Dünndarmes fand sich kein wesentlicher Inhalt, nur ein stark gallig gefärbter, dicker, zäher Schleimbelag, dessen Reaction wegeo seiner Zähigkeit schwer zu prüfen, aber an seinem unteren Ende jedenfalls nicht mehr sauer war. 9 Zoll unterhalb des Pylorus ist die Reaction deutlich alkalisch und ebenso weiter hinab durch das Jejunum und Ileum. Der Wandbelag, an mehreren Stellen mikroskopisch untersucht, zeigt hier ausserordentlich viel kleinere und feinere Fetttröpfchen, als in dem Magen, bis $z \mathfrak{u}$ den kleinsten herab in dichter Vertheilung. Die Chylusgefässe des Mesenterium präsentiren sich als milchweisse pralle Stränge; der Chylus selbst zeigt unter dem Mikroskope, wie bei Fettverdauung, neben feinen Tröpfehen das für fetthaltigen Chylus so charakteristische staubförmig fein vertheilte Fett.

Fassen wir die in diesen Versuchen gewonnenen Erfahrungen 
zusammen, so ergiebt sich daraus zunächst, dass die Curve der Resorption der Fettsäuren sehr ähnlich verläuft der von Zawilski für das Fett gefundenen: anch hier erfolgt der Uebertritt der Fettsäuren in den Chylus schon in der 2. Stunde nach ihrer Einführung in den Magen, erreicht gegen die 7. Stunde seinen Höhepunkt, auf dem er noch in der 11. Stunde verbarrt; von der 12. Stunde ab scheint die Resorptionsgrösse bereits herunterzugehen. Ferner fübren die vorstehenden Versuche zu dem bemerkenswerthen Resultat, dass nach Einführung reiner Fettsäuren eine erhebliche Steigerung im Fettgehalt des Chylus zu constatiren ist und zwar selbst unter den ungünstigsten Bedingungen der Versuche IV und VI, wo ein Theil der gefütterten Fettsäuren wieder erbrochen wurde, um das 9- bis 10 fache gegenüber der Norm, in Vers. VII um das 12 fache, in Vers. $V$ um das 17 fache und in Vers. III sogar um mehr als das 20 fache. Daneben finden sich nach Fettsäurefüterung regelmässig im Chylus freie Fettsäuren und zwar für die einstïndjge Chylusmenge von 0,026 bis hinauf zu $0,41 \mathrm{Grm}$. schwankend. Endlich ist noch die Thatsache bemerkenswerth, dass, gleichviel welches die Grösse der Resorption der Fettsäuren ist, der Gehalt des Chylus an Seifen keine erheblichen Differenzen zeigt $(0,154$ bis $0,227 \mathrm{Grm}$.), ja die Menge der nach Fettsäurefütterung in der gleichen Zeit durch den Brustgang strömenden Seifen ist nicht viel höher, als dies bei reiner Eiweissverdauung der Fall ist (nach Versuch II 0,147 Grm. Seifen). Daraus muss wohl gefolgert werden, dass die Fettsäuren überwiegend als solche in emulgirter Form und nicht als Seifen zur Resorption gelangen. Der nach Fütterung reiner Fettsäuren verbältnissmässig hohe Gehalt des Chylus an Fett und sein viel geringerer Gehalt an Fettsäuren kann wohl nicht anders gedeutet werden, als dass die Fettsäuren nicht nur resorbirt, sondern auf dem Wege von der Darmhöhle bis zum Brustgange einer Umwandlung zu Fett, einer Synthese unterlegen sind.

Ueber den Ort, wo diese Synthese erfolgt, lässt sich nur vermuthungsweise aussprechen, dass es vielleicht die Darmzotten sind, in deren Epithelien sich dieser chemische Prozess abspielt. Nach Hoppe-Seyler's ${ }^{1}$ ) Auffassung ist die Darmzotte als ein lebender

) Physiol. Chemie. II. Berlin 1877. S. 352.

A rehiv f. pathol. Anat. Bd. LXXX. Hft. 1. 
Organismus anzusehen, der von der Darmhöhle die verschiedensten Stoffe erhält, die je nach ihren Affinităten aul ihn einwirken und ihn zur chemischen Reaction veranlassen können. Im Einklang hiermit steht die von Hoppe-Seyler angeführte Thatsache, die ich bestätigen kann, „dass bei Fütterung mit Fett der Chylusstrom stark fliesst, bei Fütterung mit fettfreiem Fleisch und Kohlehydraten sich nur langsam bewegt, eine Erscheinung, die auch nur so aufgefasst werden kann, dass die Fettheilchen die Epithelzellen zu ihrer Aufnahme und Fortschaffung in die Chylusgefässe selbst anregen". Vielleicht sind aber auch die Mesenterialdrïsen, welche der Chylus auf seinem Wege von den Darmzotten zum Brustgang passiren muss, bei dieser Synthese nicht unbetheiligt. Die Thatsache, dass bei Fettsäureverdauung schon die feinsten Chylusgefässe des Mesenterium einen milchweissen Inhalt führen, vermag diese Frage nicht zu entscheiden, denn wie schon Eingangs erwähnt, kommt das milchweisse Aussehen auch alkalischen, Fettsäuren emulgint haltenden Eiweiss- und Seifenlösungen zu. Nur die chemische Analyse resp. der dadurch gelieferte Nachweis, dass schon in den Mesenteriallymphgefässen oder aber erst im Milchbrustgang bei Verdauung reiner Fettsäuren überwiegend Neutralfett sich findet, würde die Frage nach dem Orte der Synthese - ob im Zottenepithel oder den Mesenterialdrüsen - definitiv entseheiden können. Leider reichen die aus den feinen Gefässen des Mesenterium erbältlichen Tröpfehen von Cbylus für die chemische Analyse nicht hin. Die Lösung dieser Frage wird erst dann gelingen, wenn ein glücklicher Zufall ein Reagens kennen lehrt, das selbst an spärlichem Material Fette und Fettsäuren scharf von einander zu unterscheiden gestattet.

Zur Synthese von Fettsäuren zu Fett bedarf es einer gewissen Menge Glycerin und zwar etwa 1 Theil Glycerin auf 19 Theile Fettsäuren $^{1}$ ). Da in unseren Versuchen nur Fettsäuren zugeführt wurden, so hat der Organismus selbst das zur Synthese erforderliche Glycerin hergeben müssen. Woher indess dieses zur Bildung von Fett benöthigte Glycerin stammt, bleibt dabei durchaus dunkel.

Von der Anschaunng ausgehend, dass die aus den Fetten abgespaltenen Fettsäuren an Alkalien zu Seifen gebunden werden müss-

1) Wie oben (S. 12) angeführt, enthalten die thierischen Fette 95 pCt, Fettsãuren und etwa 5 pCt. Glycerin. 
ten, um der Resorption zugänglich zu werden, hat Percwoznikoff ${ }^{1}$ ) die Frage nach dem Ort, wo die Regeneration der Seifen und des Glycerin zu Fett stattfände, zu entscheiden gesucht. In der bisher allein vorliegenden, kurzen vorläufigen Mittheilung giebt er an, nur nach gleichzeitiger Injection von Seife und Glycerin in den Darm Fuillung der Zotlen mit molecularem Fett und Bildung eines gewöhnlichen weissen Chylus erhalten zu haben, während nach Injection von Seifen allein dies nicht der Fall gewesen sein soll. Meine nicht nur auf das Aussehen des Chylus, sondern auf genauere Analyse seines Gehaltes an Fettkörpern sich stützenden Untersuchungen stellen es über allen Zweifel, dass nach alleiniger Zufubrung von Fettsäuren ohne Fett und ohne Glycerin der Chylusstrom reichlich Fett führt, dass also schon aus Fettsäuren allein Fett gebildet wird. Ich habe, als von meinen Untersuchungen abliegend, methodische Versuche mit Einfiuhrung von Seifen nicht angestellt. Nur so viel habe ich mit Bestimmtheit gesehen, dass auch nach Einführung reiner Seif ${ }^{2}$ ) bei einem Hunde, der vorher 48 stunden lang gehungert hatte, in der 4. Verdauungsstunde, wo das Thier getödtet wurde, die Chylusgefässe des Mesenterium milchweiss injicirt waren, nicht anders als dies nach Fütterung mit Fettsäuren der Fall ist. Eine ähnliche Erfahrung hat neuerdings, wie es scheint, auch Hoppe-Seyler ${ }^{3}$ ) gemacht.

Was das weitere Schicksal der durch den Chylus dem Blute zugefübrten freien Fettsäuren betrifft, so ist zunächst auf Grund der bereits Eingangs citirten Untersuchungen und Angaben von Röhrig ${ }^{4}$ ) die Frage zu discutiren, ob dieselben uberhaupt als solche resp. als fettsaure Alkalien (Seifen) im Blute bestehen können. Röhrig

) Centralbl. f. d. med. Wiss. 1876. No, 48.

2) Officineller Sapo medicatus war zur Entfernung etwa darin eingeschlossezen Fettes noch wiederholt mit warmem Aether extrahirt worden.

3) Physiol. Chem. III. Berlin 1879. S. 594 heisst es: „0effuet man am lebenden Honde den Ductus thoracicus in der Näbe seiner Einmündung in die Vene wäbrend der Verdaung, so ist der Strom nor dann ein kräftiger, wenn entweder Fett oder Seife in der Nahrung enthalten ist und nun durch das enthaltene, auf das Feinste zertbeilte Fett milchweisser Chylus gebildet wird." An der schon (S. 34) citirten Stelle aus dem 1877 erschienenen II. Theil findet sich nur,$\ldots$ dass bei Fütterung mit Fett der Chylusstrom stark fliesst ....

4) Arbeit. aus d. pbysiolog. Anstalt z. Leipzig. IX. Jahrgang 1874. S. 1-23. 
hatte beobachtet, dass beim Zusatz von Seifenlösung zu Blutserum eine wolkige Trübung entsteht, die sich allmählich als krystallinischer Niederschlag von Kalkseife absetzt und darauf hin die geläufige Angabe, das Blut enthalte fettsaure Alkalien gelöst, bestritten. Auch konnte er sich bei directer Verarbeitung von Blat, selbst von fetthaltigem nicht von dem Vorkommen fettsaurer Alkalien überzeugen. Dem gegenüber möchte ich zunächst hervorheben, dass kein Untersucher, Röhrig ausgenommen, geringe Mengen an Alkalien gebundener Fettsäuren im Blute vermisst hat; es genüge dieserhalb auf die Darstellungen in den Lehrbüchern von Gorup-Besanez und von Hoppe-Seyler zu verweisen; der letztere z. B. sagt ${ }^{1}$ ), ,im Blutserum sind Palmitin- und Stearinsäure mit Alkali verbunden nachzuweisen, ebenso Oelsäure". Gegenüber jener Angabe von Röhrig darf das constante Vorkommen kleiner Mengen von Seifen im Blute um so mehr als gesichert gelten, als durch den Chylus, in welchem alle Beobachter ohne Ausnahme Seifen und zwar bis zu 2 pro mille gefunden haben ${ }^{2}$ ), dem Blute dauernd Seifen zugefuhrt werden und zwar nach unseren Bestimmungen beim Hunde in nicht sehr erheblich schwankenden Mengen, gleichviel ob nur Eiweiss verdaut wird oder die Fettresorption sich auf ihrem Höhepunkt befindet $(0,15-0,23 \mathrm{Grm}$. Seifen pro Stunde). Es werden also dem Blute durch den Chylus in der Minute etwa 2,5-4 Mgrm. Seife zugeführt, die bei der Geschwindigkeit, mit welcher der Kreislauf sich vollzieht ${ }^{3}$ ), schnell durch die gesammte Blutmenge vertheilt werden, ohne dass sie in diesen Spuren durch die Kalksalze des Blutserum ausgefällt $2 u$ werden brauchen, ist es doch auch andererseits hinreichend bekannt, dass bei Gegenwart gewisser organischer Stoffe an sich unlösliche Verbindungen, in kleinen Mengen wenigstens, in Lösung gehen können. Es ist eben etwas anderes, wenn Röhrig zu Blutserum im Cylinderglase eine relativ grosse Menge von Seifenlösung hinzufügt, als wenn dem in steter Circulation befindlichen

1) Physiolog. Chem. III. S. 433.

2) Vergl. die bei Hoppe-Seyler (Physiol. Chem. III. S. 597) citirten, sowie die vorstehenden Analysen.

3) Nach den Bestimmungen von E. Hering und Vierordt betrăgt die Umlaufszeit des Blutes, d. i. die Zeit, welche jedes Bluttheilchen braucht, um einmal den Weg durch den ganzen Kreislauf zurückzulegen, für den Hund nur etwa 17 Secunden. 
Blute in jeder Minute nur wenige Milligramm von fettsauren Alkalien sich beimischen. Dass übrigens die dem Blute durch den Cbylus zugefühten fettsauren Alkalien etwa annähernd in dem Maasse, als sie zuströmen, in den Geweben zersetzt werden, geht wohl daraus bervor, dass ungeachtet der fast stetigen Zufuhr von fettsauren Alkalien durch den Chylus das Blut immer nur Spuren davon enthält. In ähnlicher Weise wird es sich vermutblich mit den freien Fettsäuren verhalten, die bei Fettsäurefütterung neben den Seifen dem Blute in geringer Menge emulgirt zugeführt werden und zwar pro Stunde zwischen 0,03 und $0,41 \mathrm{Grm}$. oder zu $\frac{1}{2}$ bis fast $7 \mathrm{Mgrm}$. in der Minute.

Es erübrigt noch die Frage zu discutiren, ob und in wie weit aus unseren Versuchen ein Schluss auf den normalen Vorgang der Fettresorption gestattet ist. Da der Versuch festgestellt hat, dass die Fettsäuren, in Gaben bis zu $100 \mathrm{Grm}$., ebenso gut im Darme ausgenutzt werden, also in gleichem Umfange resorbirt werden, wie die entsprechenden Mengen Neutralfett, da ferner gezeigt worden ist, dass ihnen auch als Sparmittel derselbe Werth wie den Fetten zukommt, da endlich ein, jedenfalls nicht geringer Antheil von ibnen noch vor ibrem Uebertritt in die Blulbahn auf synthetischem Wege zu Fett wird, so würde kaum etwas dagegen anzuführen sein, wenn man annähme, dass auch in der Norm die Fette im Darmrohr durch das Pancreas- und Fäulnissferment in Fettsäuren und Glycerin zersetzt und diese Spaltungsproducte nach ihrem Uebertritt in die Resorptionswege wieder zu Fett regenerirt würden. Wenn wie in diesem Fall neben den Fettsäuren sich gleichzeitig Glycerin in den Resorptionsbahnen befindet, dürfte, das lässt sich annehmen, die Synthese zu Fett in noch grösserem Umfange erfolgen. Doch möchte ich betonen, dass, wenn auch dieser Hypothese nach den von mir gewonnenen Erfahrungen nichts im Wege stehen würde; sich doch aus dem Nachweis der Möglichkeit eines derartigen Vorganges für die Fettresorption noch kein bindender Schluss dahin ergiebt, dass in der Norm auch jedes Fettheilchen dieser Spaltung im Darm thatsächlich unterliegt. Einen Entscheid nach dieser Richtung erhoffe ich von Fütterungsversuchen mit Gemischen von Fettsäuren, deren Schmelzpunkt oberhalb der Temperatur des Thierkörpers liegt, Versuchsreihen, die bereits in Angriff genommen sind und die ich seiner Zeit mittheilen werde. 
Seitdem ich über die Hauptergebnisse der vorstehenden Versuche in Kürze berichtet habe ${ }^{1}$ ), ist, mehrere Monate später, eine vorläufige Mittheilung von $\mathrm{A}$. Will ${ }^{2}$ ) über Fettresorption erschienen. Dieser Autor hat hungernde Frösche theils mit Palmitinsäure und Glycerin, theils mit palmitinsaurem Natron und Glycerin gefüttert und im Darmepithel nach Behandlung mit Ueberosmiumsäure bei der mikroskopischen Untersuchung die tiefbraunschwarze Färbung wahrgenommen, welche dieses Reagens bei Fetten hervorruft. Unter Zurückweisung des nach meiner, übrigens von ihm citirten Mittheilung möglichen Einwandes, als handle es sich um Aufnahme von Körnchen der Fettsäure in Substanz und vach Wiederholung der Versuche (Injection von Fettsäure und Glycerin) am ausgeschnittenen Froschdarm mit dem nehmlichen Erfolge, wie bei der Fettsäure- resp. Seifenfütterung kommt Will zu dem Schluss, „dass die Fette, nicht wie bis jetzl von den meisten angenommen worden ist, in Form von Emulsion als Fettkügelchen aufgenommen werden, sondern dass sie innerhalb des Darmrohrs zuerst zersetzt und dabei in Fettseifen und Glycerin verwandelt werden, welche, in Wasser löslich, auf dem Wege der Diffusion in das Epithelprotoplasma eindringen, um daselbst auf's Neue als Fettregeneratoren zu dienen". Selbst geselzt, dass die von Will gemachten Erfahrungen sich bestätigten - und einer solchen Bestätigung durch schärfere analytische Methoden bedürfen sie um so mehr, als sie einzig und allein auf mikrocbemischen Reactionen fussen, deren Sicherheit nicht über jeden Zweifel erluaben ist - selbst dann, meine ich, würde der von. ihm aus Erfahrungen am Frosche allein auf die Vorgänge beim Warmblüter gezogene Schluss etwas voreilig sein. Ich habe vorhin die Gründe auseinandergesetzt, weshalb ich der Ansicht bin, dass nicht einmal aus den von mir mitgetheilten, am Sängethier angestellten und umfassenderen Versuchen sich ein bindender Schluss auf den normalen Vorgang der Fettresorption ergiebt und kann nunmehr den mikrochemischen Versuchen von Will am Froschdarm um so weniger die Berechtigung zu einem derartigen Schluss zuerkennen. Will man sich übrigens dieser Vorstellung anschliessen,

1) Verbandlungen der physiolog. Ges. zu Berlin vom 18. April 1879 No. 13, ausgegeben am 1. Mai 1879; auch abgedruckt in du Bois-Reymond's Arch. f. Physiol. 1879. S. 371.

$\left.{ }^{2}\right)$ Arch. f. d. ges. Physiol. XX. Septemberheft. S. 255-262. 
so wird man dieselbe auf Grund meiner Beobachtungen dahin corrigiren müssen, dass die aus den Fetten im Darme abgespaltenen Fettsäuren nur zum kleineren Theile in Seifen übergehen, zu einem vermuthlich grösseren Theile dagegen, durch die Seifenlösung emulgirt, als solche aufgenommen werden. Aus den von Will angeführten Versuchen möchte ich noch, als für die uns beschäftigende Frage von Interesse, einen besonders hervorheben. Will findet ${ }^{1}$ ) selbst am ausgeschnittenen Froschdarm 6 Stunden nach Einführung von Palmitinsäure und Glycerin eine reichliche Fettinfiltration des Darmepithels. Führte er nur Palmitinsäure ohne Glycerin ein, so „fand man zwar auch Fetttröpfchen in den Epithelien, doch waren dieselben lange nicht so zahlreich, wie in den Fällen, in welchen die eingeführte Palmitinsäure Glycerin beigemengt enthielt". Wenn also nach Einführung von Fettsäuren allein schon Fetttröpfchen im Darmepithel, nur weniger reichlich als nach Beigabe von Glycerin sich finden, so heisst das eben nichts anderes, als dass schon aus Fettsäuren allein Fette werden können. Ich möchte diesen Punkt um so mehr hervorheben, als Will diese interessante Erfahrung ohne jeden Commentar mittheilt.

Die vorstehend mitgetheilten Fütterungs- und Ausnutzungsversuche sind in dem chemischen Laboratorium des pathologischen Instituts, dessen Leiter, Herrn Professor E. Salkowski, ich für manchen freundlichst ertheilten Rath mich zu aufrichtigem Dank verpflichtet fühle, die vivisectorischen Versuche im physiologischen Laboratorium der k. Thierarzneischule ausgeführt worden.

2. Die physiologische Bedeutung des Glycerin.

Nach den im ersten Theil dieser Abhandlung dargelegten Untersuchungen darf nunmehr als festgestellt gelten, dass den festen Fettsäuren der nehmliche Einfluss auf den Eiweissumsatz im Körper zukommt, als den chemisch äquivalenten Mengen von Neutralfett. Schon diese Thatsache dürfte zu der Folgerung berechtigen, dass der neben den Fettsäuren vorhandene andere Component des Neutralfettes, das Glycerin keinen nennenswerthen Einfluss auf die Grösse der Eiweisszersetzung im Thierkörper ausübt. In der That haben meine schon vor mehr als zwei Jahren angestellten Fütte-

1) a. a. 0. S. 260. 
rungsversuche mit Glycerin, über die ich früher berichtet babe ${ }^{1}$ ), $\mathrm{zu}$ dem sicheren Ergebniss geführt, dass das Glycerin nicht im Stande ist, nach Art anderer Nährstoffe, wie der Kohlehydrate oder Fette, einen wenn auch nur geringen Antheil von Nahrungs- oder Körpereiweiss vor dem Zerfall zu bewahren. Die unabhängig von mir in Voit's Laboratorium angestellte, aber später publicirte Versuchsreihe von L. Lewin ${ }^{2}$ ) und die Wiederholung derselben seitens N. Tschirwinsky ${ }^{3}$ ) haben diese zuerst von mir festgestellte Thatsache im Wesentlichen bestätigt. Lewin kommt zu dem Schluss ${ }^{4}$ ): „Mit den voranstehenden Versuchen ist entschieden, dass das Glycerin keinen Einfluss auf die Grösse der Eiweisszersetzung ausübt, wie das Fett oder die Kohlehydrate unter gewöhnlichen Umständen“ und Tschirwinsky, der die Angabe macht, dass bei grossen Gaben $(100-200 \mathrm{Grm}$.) Glycerin ein erheblicher Theil (37-60 pCt.) von diesem im Harn nachzuweisen ist, sagt: „Wenn nun nach Darreichung grösserer Mengen von Glycerin entweder ein stark reducirender Stoff oder sogar Glycerin als solches im Harn auftritt, so wird es wahrscheinlich, dass das Glycerin auch in Beziehung der Ersparniss von Fett im Organismus kein Nahrungsstoff ist oder nur ein geringwerthiger". Demnach können die Erfahrungen der genannten Autoren als werthvolle Bestätigungen meiner früheren Beobachtungen gelten. Stimmen nun auch unsere Resultate in den wesentlichen Punkten überein, so finden sich indess in den Mittheilungen jener Autoren theils Angaben, theils Auffassungen von so zu sagen principieller Natur, dass ich es mir nicht versagen kann, hierauf näher einzugehen und meinen von dem ihrigen abweichenden Standpunkt scharf zu präcisiren. Die Darstellung meines verehrten Collegen Lewin ${ }^{5}$ ): „J. Munk hat neuerdings bei einem Hunde von 20 Kilo Gewicht, den er mit Fleisch und Speck in's N-Gleichgewicht brachte, mehrere Tage hindurch je $25-30 \mathrm{Grm}$. Glycerin gegeben ..."

1) Verhandlungen d. physiolog. Ges. zu Berlin vom 13. December 1878; ausführlich mitgetheilt in diesem Archiv Bd. 76. S. 119-135.

2) Ueber den Einfluss des Glycerins auf den Eiweissumsatz. Zeitschr. f. Biologie. XV. S. 243-251.

3) Ueber den Einfluss des Glycerins auf die Zersetzung des Eiweisses im Thierkörper. Ebendaselbst S. 252-260.

4) a. a. 0. S. 249.

s) a. a. 0. S. 246 . 
könnte den Glauben erwecken, ich hätte in der That nur eine Versuchsreihe an einem Hunde durchgeführt, ein Umstand, der die Berechtigung meiner daraus gezogenen Schlüsse in Frage stellen könnte, gilt es doch sonst und mit Recht für gewagt, mit nur einem Versuche eine Frage als gelöst $\mathrm{zu}$ betrachten. In meiner von Lewin citirten Arbeit $^{1}$ ) findet man aber vier Versuchsreihen vollständig durchgeführt und eine jede von ihnen führt zu dem gleichen Ergebniss, nehmlich dass durch Einverleibung von Glycerin der Eiweisszerfall nicht nachweisbar modificirt wird, während eine Ersparniss im Eiweissumsatz sofort in die Erscheinung tritt, sobald statt des Glycerin die gleichen Mengen von einem notorischen Nährstoff z. B. Rohrzucker ${ }^{2}$ ) verfüttert werden. Ich hatte ferner angefübrt, dass bei einer täglichen Gabe von $40-50 \mathrm{Grm}$. Glycerin die Thiere schon am zweiten Tage diarrhoische Entleerungen bekamen und dass ich von höheren Dosen, als $30 \mathrm{Grm}$. für den Tag oder $1 \frac{1}{2}$ Grm. pro Kilo Thier Abstand genommen habe, weil beim Bestehen von Diarrhöen nicht mehr von einem normalen Ablauf der Verdauungs- und Resorptionsvorgänge im Darm die Rede sein kann. Ferner hatte ich des Genaueren ausgeführt ${ }^{3}$ ), weshalb zum Entscheid der Frage nach dem Einfluss eines Stoffes auf den Eiweissumsatz es nicht genügt, einzig und allein den durch den Harn ausgeschiedenen Stickstoff zu berücksichtigen, dass vielmehr auch die Grösse der N-Ausscheidung durch den Koth in Betracht gezogen werden muss. Die von Lewin ausgeführte Versuchsreihe und ebenso die von Tschirwinsky unterscheiden sich vou den meinigen abgesehen davon, dass jene Forscher grössere Mengen von Glycerin verfüttert baben, im Wesentlichen auch dadurch, dass von ihnen nur die Harnstoffausscheidung für die Grösse des Eiweissumsatzes berücksichtigt ist. Nun habe ich gezeigt, dass schon bei mittleren Gaben von Glycerin, schon bei $25-30 \mathrm{Grm}$, die doch noch keine diarrhoiscben Entleerungen * verursachen, mehr Stickstoff mit dem Koth ausgestossen wird, zuweilen bis zu 75 pCt. mehr und dass

1) Dieses Archiv Bd. 76. S. 126.

$\left.{ }^{2}\right)$ Rohrzucker steht hinsichtlich seiner elementaren Znsammensetzung (insbesondere des C-Gehalts) dem Glycerin sehr nahe und chemisch lhm wohl auch nicht fern; Glycerin ist als ein dreiatomiger Alkohol der Propylreihe, die Kohlehydrate wahrscheinlich als sechsatomige Alkohole aufzufassen.

s) a. a. 0. S. 122 . 
demnach das Glycerin schon bei Einführung mittlerer Gaben in den Magen eine weniger gute Ausnutzung des verfütterten Eiweiss zur Folge hat. Um wie viel mehr wird dies der Fall sein, wenn, wie im Versuche von Lewin unter dem Einfluss steigender Glycerindosen Diarrhöen auftreten, wie solche an zwei Tagen verzeichnet sind. Tschirwinsky schätzt, den von Voit gemachten Erfahrungen entsprechend, die N-Entleerung mit dem Koth während der Periode des N-Gleichgewichts einfach ab; wie sich die Fäcalentleerung während der Glycerin-Periode verbalten bat, davon geschiebt nirgends Erwäbnung. Ist somit die Menge des mit dem Koth entleerten $\mathbf{N}$ nicht bekannt, so fehlt jeder Maassstab für die Menge des aus dem Futter aufgenommenen Eiweisses, somit auch jeder Anhalt für die im Verhältniss zur resorbirten Eiweissmenge grössere oder geringere $\mathrm{N}$-Ausscheidung durch den Harn. Dass aber infolge von Diarrhöen sich ein erheblicher Theil vom Eiweiss im Futter der Resorption entzieht und mit dem Kothe ausgestossen wird, ist eine allbekannte Erfahrung. Wenn also ungeachtet der geringeren Resorption von Eiweiss die N-Ausscheidung durch den Harn gleich bleibt oder um ein Weniges - bei Lewin um kaum 2 pCt. noch ansteigt, so ist daraus nur zu schliessen, wie dies auch Lewin andeutet, dass das Glycerin eher eine geringe Erhöhung der Eiweisszersetzung, jedenfalls aber keine Ersparniss im Eiweissumsatz bewirkt.

Wesentlich weiter geht Tschirwinsky. Schon Lewin bemerkt und Tsehirwinsky führt es weiter aus, dass unter dem Einfluss grosser Gaben von Glycerin die Harnmenge, wie bekannt, auf das $1 \frac{1}{2}-1 \frac{3}{4}$ fache ansteigen kann und dass entsprechend der vermehrten Harnmenge auch die Harnstoffmenge wächst, indem durch den stärkeren Wasserkreislauf der Eiweisszerfall gesteigert wird, dass daher infolge der vermehrten Diurese die Zablen für die Harnstoffausscheidung während der Glycerinperiode so hoch ausfallen. Daraus schliesst Tschirwinsky, dass das Glycerin „offenbar in grösseren Dosen an und für sich eine Verminderung der Harnstoff bildung hervorbringt, wie das Fett oder die Kohlehydrate, dass es aber durch die Entziehung von Wasser und die Erzeugung einer reichlichen Harnmenge eine Steigerung des Eiweissumsatzes bedingt". Hiermit kann ich mich nicht einverstanden erklären. In Lewin's Versuch stieg die Harnmenge von $598 \mathrm{Cem}$. (Mittel der Normal- 
periode) bei $50 \mathrm{Grm}$. Glycerin auf $750 \mathrm{Ccm}$., bei $100 \mathrm{Grm}$. auf $910 \mathrm{Ccm}$, bei $200 \mathrm{Grm}$. auf $1080 \mathrm{Ccm}$; sie beträgt also im Mittel der Glycerinperiode $838 \mathrm{Ccm}$, mithin eine Zunabme gegen die Normalperiode um etwa 40 pCt. Non wird aber der Einfluss der vermehrten Diurese an sich auf die Harnstoffausscheidung zumeist überschätzt. A. Fränkel ${ }^{1}$ ) hat beim hungernden Hunde, ungeachtet der Zunahme der Harnvolumina (infolge Wassereinspritzungen in den Magen) bis fast auf das Fünffache, die Harnstoffausscheidung güustigsten Falls nur um 11 pCt. zunehmen sehen. Versuche von E. Salkowski und mir $^{2}$ ) an Hunden im N-Gleichgewicht haben ergeben, dass bei einer Zunahme der Harnmenge um mehr als die Hälfte sich die Steigerung der N-Ausscheidung durch den Harn auf kaum 3 pCt. beläuft. Die von Lewin gefundene Zunahme der Harnstoffausscheidung um weniger als $2 \mathrm{pCt}$. genügt dembach vollkommen, um auf Rechnung der vermehrten Diurese geselzt zu werden; abzüglich der durch letztere bedingten Steigerung würde bei Darreichung von Glycerin dieselbe Grösse der Harnstoffausscheidung bestanden haben, als vorher obne Glycerin. In Tschirwinsky's Versuch beträgt die Harumenge in der Vorperiode (im Mittel) $1051 \mathrm{Ccm}$., bei $100 \mathrm{Grm}$. Glycerin sogar nur $984 \mathrm{Ccm}$. (Durchschnitt von 4 Tagen) und steigt erst bei $200 \mathrm{Grm}$. auf $1575 \mathrm{Ccm}$. (Mittel von 2 Tagen) an. Bei Darreichung von je $100 \mathrm{Grm}$., einer Dose, bei der, wie erwähnt, eher eine Verminderung der Diurese sich geltend machte, fand Tschirwinsky an den 4 Versuchstagen: 54,1$47,5-50,3-57,5 \mathrm{Grm}$. Harnstoff. Aber selbst wenn diese so ausserordentlich variirenden Werthe für die Harnstoffausscheidung, Werthe, deren Maxima und Minima um 21 pCt. differiren, überhaupt einen Schluss gestatten, selbst wenn es danach den Anschein gewönne, als ob die Harnstoffausscheidung unter dem Einflusse von Glycerin um mehr als $4 \mathrm{pCt}$. abgenommen hätte, so würde sich doch daraus kein bindender Schluss auf eine dem entsprechende Herabsetzung des Eiweisszerfalls ergeben, da wie gesagt dazu zum mindesten erforderlich wäre, die Grösse der N-Ausscheidung durch den Koth zu kennen, diese aber in Tschirwinsky's Versuch einen völlig unbekannten Factor darstellt. Gerade in Rücksicht darauf, dass bei grösseren Gaben von Glycerin leicht diarrboische Ent-

) Dleses Archiv Bd. 70. S. 56 .

2) Dieses Archiv Bd. 71. S. 408. 
leerungen eintreten, habe ich, wie auch in meiner Arbeit angeführt, mich darauf beschränkt, nicht mehr als $1,5 \mathrm{Grm}$. pro Kilo Thier zu verfültern, weil nur bei diesen Gaben, soweit dies aus den Allgemeinerscheinungen und der Beschaffenbeit des Kothes hervorgeht, weder die Verdauung noch die Resorption noch sonst das Befinden des Thieres eine erbebliche Alteration zeigt. Uebrigens, meine ich, dürfte doch an einen Stoff, dem die Bedeutung eines Nährstoffes zuerkannt werden soll, in erster Linie die Forderung zu stellen sein, dass er weder die Vorgänge der Verdauung und Resorption noch das Allgemeinbefinden des Thieres beeinträchtigt. Nun hat sich durch meine Versuche herausgestellt, dass innerhalb der Grenzen, in welchen man dem Organismus Glycerin ohne sichtlichen Nachtheil einverleiben kann, dasselbe nicht im Stande ist, den Eiweisszerfall herabzusetzen, während dies durch die gleiche Menge eingeführter Kohlehydrate schon in unverkennbarer Weise geschieht, folglich muss man wohl schliessen, kommt dem Glycerin die Eigenschaft eines Sparmittels, wie dem Fette oder den Kohlehydraten auch nicht einmal in geringem Grade, sondern überhaupt nicht zu.

Bezüglich der Schicksale des Glycerin hatte ich angeführt, dass, da nach Einverleibung von $25-30 \mathrm{Grm}$. beim Hunde und von $20 \mathrm{Grm}$. beim Menschen sich weder unzersetztes Glycerin, noch sonst eine reducirende Substanz im Harn nachweisen lässt, man daraus - wenigstens für die in Rede stehenden Dosen - auf eine rasche und vollständige Zersetzung des Glycerin im Organismus schliessen müsse. Wird aber der Körper mit grossen Mengen von Glycerin so zu sagen überschwemmt, so tritt - und dies ist nicht wunderbar, sehen wir doch das Nehmliche auch bei anderen Substanzen, die sonst der Zersetzung unterliegen - ein Theil des Glycerin unverändert aus dem Körper heraus. Es lässt sich nicht absehen, in wie weit die von M. Rubner und Tschirwinsky ${ }^{1}$ ) in Anwendung gezogene, indirecte Methode der quantitativen Glycerinbestimmung, bei welcher aus dem Lösungsvermögen des Harns für Kupferoxyd auf den procentarischen Gehalt an Glycerin geschlossen wird, auf Schärfe Anspruch machen kann. Nehmen wir sie zunächst als hinreichend genau an, so wïrde aus diesen Bestimmungen hervorgehen, dass von $100 \mathrm{Grm}$. Glycerin beim Hunde nur 45-63 Grm., von $200 \mathrm{Grm}$. Glycerin nur etwa $70 \mathrm{Grm}$. im Organismus zersetzt

1) a. a. 0. S. 257 . 
werden. Dass im Körper des Hundes also 25-30 Grm. Glycerin, wie aus den von mir ausgeführten Harnuntersuchungen hervorgeht, durch Oxydation vollständig verschwinden, auch dafür liefern die von Tschirwinsky gemachten Erfahrungen eine erfreuliche Bestätigung, ist doch nach diesem Autor der Organismus des Hundes eine selbst doppelt so grosse Menge zu zersetzen im Stande.

In meinen Fütterungsversuchen mit Salmiak ${ }^{1}$ ), mit Glycerin ${ }^{2}$ ) und mit Fettsäuren habe ich die auf die einzelnen Perioden entfallenden Kothantheile durch Korkstücke abgegrenzt, welche einige, mindestens 8 Stunden vor Ablauf der resp. Perioden dem Hunde gereicht wurden. Die Korkstücke finden sich alsdann im Koth neben einander vor und bilden auf diese Weise eine Abgrenzung, die, eine sorgfältige Ueberwachung der Kothentleerung und die Consistenz normalen Koths yorausgesetzt, durchaus scharf hervortritt. Ich hätte mir nicht denken können, dass diese Darstellung zu einem höchst seltsamen Missverständnisse würde Anlass geben können. In der Arbeit von M. Rubner , über die Ausnutzung einiger Nahrungsmittel etc." findet sich in einer Anmerkung erwähnt ${ }^{3}$ ), dass N. Tschirwinsky im Münchener physiologischen Institute zwei Versuche mit jener von mir vorgeschlagenen Methode angestellt hat, aber zu keinem zufriedenstellenden Ergebniss gelangt ist. Aber wie ist Tschirwinsky bei der Nachprüfung meines Vorschlags verfahren? Er giebt einem hungernden Hunde, der vor 24 Stunden zum Zweck der Kothabgrenzung Knochen erhalten hatte, früh um 7 Uhr 144, sage ein Hundert vier und vierzig Korkstückchen, dann schon nach 6 Stunden $800 \mathrm{Grm}$. Fleisch und ist sehr verwundert, dass die 144 Korkstücke statt zwischen Knochen- und Fleischkoth im Fleischkoth stecken. In einem anderen Versuche werden sogar 150 Korkstücke zwischen Fleisch- und Brodnahrung gereicht; es fand sich ein Drittel davon schon im Fleischkoth wieder, die anderen zwei Drittel im Brodkoth. Mich hat es nun nicht im mindesten gewundert, dass Tschirwinsky zu solch' einem Resultate gelangt ist; denn ich wüsste nicht, wie 144-150 Korkstücke in der Continuität eines Kothballens zwischen Knochen- und Fleisebkoth resp. Fleisch- und Brodkoth Platz haben sollen. Tschirwinsky giebt

1) Zeitschr. f. physiol. Chem. II. S. 31.

2) Dieses Archiv Bd. 71. 5. 125.

s) Zeitschr. f. Biologie. XV. S. 11 5. 
doch sicherlich Knochen zur Kothabgrenzung auch nicht gleich zu Hundert Grammen! Um nun für die Zukunft einem ähnlichen Missverständnisse, an dessen Möglichkeit ich allerdings nie gedacht habe, vorzubeugen, will ich durch minutiöse Beschreibung eines Versucbsbeipiels genauer angeben, wie ich verfahre. Ein für Stóffwechselversuche eingeübter Hund von etwa 23 Kilo erhjelt nach zweitägigem Hungern am 17. Juli $187910 \mathrm{Uhr}$ Vormittags $600 \mathrm{Grm}$. Fleisch nebst $70 \mathrm{Grm}$. Speck; Abends 7 Uhr wurden ihm zum Zwecke der Kothabgrenzung 4 Korkstücke bejgebracht, welche aus einem Kork von $27 \mathrm{Mm}$. Höhe und $13 \mathrm{Mm}$. Durchmesser geschuitten waren, sodass ein jeder etwa $7 \mathrm{Mm}$. Höhe bei $13 \mathrm{Mm}$. Durchmesser hatte. Alsdann erhielt er am 18. Juli Morgens und ebenso an den folgenden Tagen ausschliesslich Schwarzbrod. Erst am 21. Juli Mittags entleerte er zwei Kothballen, von denen der erstere, kleinere aus reinem Fleischkoth, der andere an dem zuerst ausgestossenen Ende aus pechschwarzem Fleischkoth bestand und weiterhin in den gelbbraunen, weicheren Brodkoth überging. Auf Querschnitten dieses zweiten Kothballens, welche von fast Centimeter zu Centimeter angelegt wurden, zeigte es sich nun - und Herr Prof. Salkowski hat die Freundlichkeit gebabt, diesen Befund zu controliren -, dass die ersten beiden Korkstücke dicht neben, aber zum Theil schon binter einander im Fleischkoth lagen, doch so, dass das zweite mit seinem schmäleren Segmente schon in den gelbbraunen Brodkoth hineinragte. Die beiden anderen Korke fanden sich, von den ersteren noch nicht durch eine Centimeter-lange Kothschicht getrennt, im Anfangsstücke des Brodkotbs wieder. Wenn man dem gegenüber in Betracht zieht, dass bei der Abgrenzung z. B. des Fleischkoths durch Knochen oft eine mehrere Centimeter lange graue Schicht gefunden wird, innerhalb deren Reste des Fleischkoths mit dem weissen Knochenkoth innig gemischt sind und erst dann die fast weisse Zone des reinen Knochenkoths folgt, dass also hier die so zu sagen indifferente Zone nicht selten breiter ist, als in dem angeführten Fall, wo die Entfernung zwischen den Korkstücken noch nicht $1 \mathrm{Cm}$. betrug, so wird man mir darin jedenfalls beipflichten, dass meine Methode sicherlich nicht schlechtere Resultate giebt, als die bisher nach Voil's Vorschlag gelibte, welche, um nur einen Nachtheil hervorzuheben, sich infolge der Knochensalze störend geltend macht, wenn es sich z. B. um die Bestimmung der festen Be- 
standtheile und des Aschengehalts der Fäces handelt. Ich meinestheils zweifle nicht, dass Tschirwinsky bei Verwendung eines dreissig mal kleineren Abgrenzungsmaterials zu besseren, ihn selbst befriedigenden Resultaten gelangen wird.

Alles zusammengebalten, kann ich mich nicht veranlasst sehen, meine früher mitgetheillen Anschauungen über die physiologische Bedeutung des Glycerin in irgend welcher Beziehung zu modificiren, muss vielmehr auch jetzt noch daran festhalten, dass das Glycerin weit davon entfernt ist, ein Nährstoff nach Art der Kohlehydrate oder Fette zu sein.

\section{III. \\ Anleitung zum Studium der Medicin aus den Jahren 1533 und 1340.}

(Meist nach handschriftlichen Quellen.)

Von H. Tollin, Lic. theol. in Magdeburg.

Wenn wir für das secbszehnte Jahrhundert eine vollständige und zuverlässige Mortalitätsstatistik hätten, wie wir sie heute in Deutschland, Frankreich, Italien und England sich anbahnen sehen; oder vielmehr, wenn wir für jene Zeit eine Statistik einer anatomisch geprüften und bewährten Aetiologie besässen und eine ebenso gute für die Jetztzeit, so könnten wir mit einer gewissen Wahrscheinlichkeit - denn darüber hinaus kommt (nach Aristoteles) die Wissenschaft nie - ein festes Urtheil uns erlauben, ob heute durch die Aerzte mehr Krankheiten abgewandt, geheilt oder erlejchtert worden sind, melir kranken Menschen das Leben gerettet, mehreren ihre Tage verlängert und schmerzloser gestaltet wurden, als ehemals?

So lange wir aber jene Statistik nicht besitzen, wird man auf Vermuthungen angewiesen bleiben. Und da geht zu allen Zeiten die grosse Volksströmung nach-der Richtung hin, zu glauben, dass früber die Menschen (durch die Aerzte, ohne die Aerzte oder trotz der Aerzte) kräftiger gewesen sind, Anstrengungen besser ertragen, mehr Charakterstärke gezeigt und ein längeres, glücklicheres Leben 